\title{
Dynamic Responses of Simply Supported Girder Bridges to Moving Vehicular Loads Based on Mathematical Methods
}

\author{
Qingfei Gao, ${ }^{1,2}$ Zonglin Wang, ${ }^{1}$ Binqiang Guo, ${ }^{3}$ and Chuang Chen ${ }^{1}$ \\ ${ }^{1}$ School of Transportation Science and Engineering, Harbin Institute of Technology, Harbin 150090, China \\ ${ }^{2}$ Department of Civil and Environmental Engineering, National University of Singapore, Singapore 117576 \\ ${ }^{3}$ Zhejiang Provincial Institute of Communications Planning, Design and Research, Hangzhou 310000, China
}

Correspondence should be addressed to Qingfei Gao; gaoqingfei1986@gmail.com

Received 30 June 2014; Revised 18 August 2014; Accepted 19 August 2014; Published 29 September 2014

Academic Editor: Jun Cheng

Copyright (C) 2014 Qingfei Gao et al. This is an open access article distributed under the Creative Commons Attribution License, which permits unrestricted use, distribution, and reproduction in any medium, provided the original work is properly cited.

\begin{abstract}
For dynamic responses of highway bridges to moving vehicles, most of studies focused on single-factor analysis or multifactor analysis based on full factorial design. The defect of the former one is that it has no consideration of interaction effects, while that of the latter one is that it has large calculation. To avoid these defects, simplified theoretical derivations are presented at first; then some numerical simulations based on the proposed method of the orthogonal experimental design in batches have been done by our own program VBCVA. According to simplified theoretical derivations, three factors $(\kappa, \gamma$, and $\alpha)$ are proved as the most important factors to determine dynamic responses. Based on the modal synthesis method, the program VBCVA has been introduced in detail. Then on the basis of the orthogonal experimental design, both main effects and interaction effects are studied. The results show that, for different indices of dynamic responses, the influences of each factor are not the same. Additionally, the interaction effects have proved to be so small that they can be neglected. In the end, this method provides a good way to obtain more rational empirical formulas of the DLA and other dynamic responses, which may be adopted in the revision of codes for design and evaluation.
\end{abstract}

\section{Introduction}

Research on the dynamic analysis of the vehicle-bridge coupled vibration system is an important issue in civil engineering [1]. As for this problem, three methods are used in general, including the theoretical derivation, dynamic loading test, and numerical simulation.

As moving vehicles on the bridge vary in both time and space, the problem becomes more complex. And it has been noted more than 100 years before. A lot of researchers tried to obtain the effects of moving load on various elements, components, and structures based on theoretical derivations. It had been well reviewed by Frýba [2]. In 1989, an analyticalnumerical method was presented that could be used to determine the dynamic behavior of beams, with different boundary conditions, carrying a moving mass [3].

The specification about impact factor or dynamic load allowance in most of design codes was obtained based on the dynamic loading test. The first thorough investigation of highway bridge dynamic loading was conducted from 1922 to 1928 by an ASCE committee (10 bridges) [4]. In the years 1958 to 1981, the Section Concrete Structure of the EMPA performed load tests on 356 bridges, and 226 static and dynamic tests on slab and beam-type highway bridges were of interest at last [5]. In Canada, three large scale series tests were completed. Firstly, a group of 52 bridges known to vibrate was selected for test in the years 1956 to 1957. Secondly, many tests were completed on continuous concrete bridges in the years 1969 to 1971 . Thirdly, a total of 27 bridges were selected in 1980, which was the main basis of the design code OHBDC [6]. In China, the specification in current code was obtained from the test data of 7 simply supported girder bridges [7]. In Korea, from 1995 to 2007, a total of 256 bridges, of which span varied from $10 \mathrm{~m}$ to $160 \mathrm{~m}$, were tested and analyzed to suggest new design criteria for an impact factor which was based on a natural frequency rather than the span length [8].

However, not all researchers can study the problem by dynamic fielding tests due to the budgets limitations. In recent years, with the development of computers, numerical simulation studies are widely used. The dynamic behavior of 
simple-span [9] and continuous [10] highway bridges under moving vehicles were studied based on a method of analysis which idealized the bridge as a single beam and represents the vehicle as a multiaxle sprung load. Wang et al. [11] studied the dynamic behavior of multigirder bridges, which was modeled as a grillage beam system, due to vehicles with 7 and 12 degrees of freedom (H20-44 truck and HS20-44 truck) moving across rough bridge decks. A general and efficient method was proposed for the resolution of the dynamic interaction problem between a bridge, discretized by a three-dimensional finite element model, and a dynamic system of vehicles running at a prescribed speed [12]. To study the interaction problem of large complicated bridges with various types of running vehicles, a fully computerized approach for assembling equations of motion of any types of coupled vehiclebridge system [13]. Apart of this, many researchers focused on more complicated modeling of the vehicle-bridge system [1416], which are much more similar with the actual conditions.

According to the review of existing literature, the defects and shortages are listed as follows.

(i) The vehicle-bridge coupled model is oversimplified, especially in theoretical derivation. And it is largely different from the actual conditions.

(ii) The selection of influence factors is subjective, and it lacks sufficient theoretical basis. As for one problem, the understanding from different engineers may be largely different, even if opposite.

(iii) The interaction effects are seldom studied in the dynamic analysis of the bridge to moving vehicles. Most of studies focused on main effects.

(iv) Abundant calculations are needed in the method of full factorial design, which has been used for multifactors problem before.

(v) The impact factor in current code is the function of single parameter. It has been proved not rational and should be revised.

Therefore, the method of orthogonal experimental design in batches has been proposed in this paper. It can be used for studying both the main effects and the interaction effects. Meanwhile, due to the processing in batches, it greatly reduces the calculation cost. To make a good understanding of the vehicle-bridge system and to obtain the basis of the selection of some important factors, two simplified models are discussed at first. As a basic calculation tool, which will be more consistent with the actual condition, our own program VBCVA is described in detail. At last, using the proposed method, the influences of twelve common factors and some of their interaction effects on dynamic responses of the vehiclebridge coupled system are discussed.

For safety of bridges, the impact factor is usually adopted to account for the dynamic responses induced by moving vehicles. However, there are many different names [17], which are always confused in the research and engineering application. So we should restate it here. In this study, two terms are used, the dynamic load allowance (DLA, $\eta$ ) and the impact factor (IF, $\mu$ ). And the definitions of them can be given by

$$
\eta=1+\mu=\frac{y_{d, \max }}{y_{s, \max }}
$$

in which the $y_{d, \max }$ and $y_{s, \max }$ denote, respectively, the maximum value of the dynamic response and the static response. It has to be noted that the position of the vehicle where the maximum dynamic response occurs is different from that related with the maximum static response in general.

In addition, for comfort analysis of pedestrians and passengers or drivers, the vibration accelerations of the bridge and the vehicle are adopted, because a large number of researchers have obtained the conclusion that the comfort of people is mainly determined by the acceleration [18-22].

\section{Theoretical Derivation on Simplified Models}

Theoretical derivation on simplified models does not quite agree with the actual situation, but it is one of the best ways to determine the key parameters and their influences on the dynamic responses. And, according to the derivation, the physical meanings may be more obvious, which will be good guidance for design and evaluation on dynamic performance of the highway bridge to moving vehicular loads. Consequently, in the beginning of this study, the dynamic responses of a simply supported girder bridge traversed by a single moving constant load and a moving sprung mass which are deduced and discussed, respectively.

2.1. Simply Supported Girder Bridges Traversed by a Single Moving Constant Load. Of the wide range of problems involving vibration of structures subjected to a moving load, the easiest one to tackle is that of dynamic responses in a simply supported girder bridge (or a simply supported beam), traversed by a constant force moving at uniform speed [23]. This classical case was first solved by Krylov [24], then by Timoshenko [25]. Other solutions worthy of mention are those by Inglis [26] and Koloušek and McLean [27].

If the weight of the vehicle is far smaller than that of the bridge, the inertia force of the vehicle can be ignored. Then the vehicle-bridge coupled system can be simplified as a simply supported girder bridge traversed by a single moving constant load (Figure 1).

Based on the theory of the structural dynamics, the governing equation of the bridge can be given by

$$
\begin{array}{r}
m \frac{\partial^{2} u_{b}(x, t)}{\partial t^{2}}+c \frac{\partial u_{b}(x, t)}{\partial t}+E I \frac{\partial^{4} u_{b}(x, t)}{\partial x^{4}}= \\
P \delta(x-v t) \\
0 \leq v t \leq L
\end{array}
$$

in which the $P$ denotes the constant force, $L, m, c, I, E, u_{b}$, $x, t$, and $v$ denote, respectively, the span length, mass per unit length, damping, moment of inertia, elasticity modulus, displacement, location, time, and the moving speed. And $\delta$ is the Dirac-delta function.

The initial displacement and velocity are assumed as zero. As for simply supported girder bridge, the sine functions can 


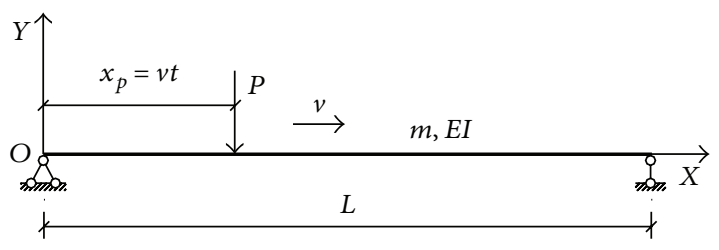

Figure 1: A single moving constant load.

be assumed as the mode shapes $\left(\varphi_{n}(x)\right)$. Also, the dynamic displacement and the bending moment in the support section are zero. Based on the mode superposition method, the dynamic displacement of the bridge can be given by

$$
\begin{aligned}
& u_{b}(x, t) \\
& =\sum_{n=1}^{N} \frac{1}{n^{4}} \frac{2 P L^{3} /\left(\pi^{4} E I\right)}{\left(2 \xi_{b n} \alpha_{n}\right)^{2}+\left(1-\alpha_{n}^{2}\right)^{2}} \\
& \times\left\{\left[\left(1-\alpha_{n}^{2}\right) \sin \omega_{d n} t-2 \xi_{b n} \alpha_{n} \cos \omega_{d n} t\right]\right. \\
& +e^{-\xi_{b n} \omega_{b n} t}\left[2 \xi_{b n} \alpha_{n} \cos \omega_{c n} t+\left(2 \xi_{b n}^{2}+\alpha_{n}^{2}-1\right)\right. \\
& \left.\left.\times \frac{\alpha_{n}}{\sqrt{1-\xi_{b n}^{2}}} \sin \omega_{c n} t\right]\right\} \sin \frac{n \pi x}{L},
\end{aligned}
$$

where $\xi_{b n}$ is the damping ratio corresponding to the $n$th mode shape and $\omega_{b n}, \omega_{c n}$, and $\omega_{d n}$ are, respectively, the $n$th natural frequency of the bridge without damping and with damping and the disturbance frequency which is dependent on the speed of the moving vehicle and the $n$th mode shape of the bridge. And $N$ is the number of all considered mode shapes. Furthermore, an important nondimensional parameter $\alpha_{n}$ is introduced. The relations of these parameters are listed as follows:

$$
\begin{gathered}
\xi_{b n}=\frac{c}{2 m \omega_{b n}}, \\
\omega_{b n}=\left(\frac{n \pi}{L}\right)^{2} \sqrt{\frac{E I}{m}} \\
\omega_{c n}=\omega_{b n} \sqrt{1-\xi_{b n}^{2}}, \\
\omega_{d n}=\frac{n \pi v}{L}, \\
\alpha_{n}=\frac{\omega_{d n}}{\omega_{b n}}=\frac{n \pi v}{\omega_{b n} L} .
\end{gathered}
$$

According to (3), if the damping of the bridge is ignored, the dynamic displacement can be simplified as

$$
\begin{aligned}
u_{b}(x, t)= & \sum_{n=1}^{N} \frac{1}{n^{4}} \frac{2 P L^{3} / \pi^{4} E I}{1-\alpha_{n}^{2}} \\
& \times \sin \frac{n \pi x}{L}\left[\sin \omega_{d n} t-\alpha_{n} \sin \omega_{b n} t\right] .
\end{aligned}
$$

It can be seen from (5) that there are two parts in the dynamic displacement of the simply supported girder bridge traversed by a single moving constant load. One part is the forced vibration related to the speed of the moving load, and the other part is the free vibration of the bridge itself.

If the speed of moving load is zero, but the force vibration in (5) is still retained, the static displacement of the bridge $\left(u_{s}\right)$ is obtained as

$$
u_{s}\left(x, x_{p}\right)=\sum_{n=1}^{N} \frac{1}{n^{4}} \frac{2 P L^{3}}{\pi^{4} E I} \sin \frac{n \pi x}{L} \sin \frac{n \pi x_{p}}{L},
$$

where $x$ and $x_{p}$ are, respectively, the locations of the bridge section and the load.

In accordance with theory of structural statics [28], the accurate static displacement can be given by

$$
\begin{aligned}
& u_{s}\left(x, x_{p}\right) \\
& =\left\{\begin{array}{c}
\frac{P L^{3}}{6 E I}\left(1-\frac{x_{p}}{L}\right)\left[1-\left(1-\frac{x_{p}}{L}\right)^{2}-\left(\frac{x}{L}\right)^{2}\right] \frac{x}{L}, \\
0 \leq x \leq x_{p}, \\
\frac{P L^{3}\left[\left(\frac{x}{L}-\frac{x_{p}}{L}\right)^{3}\right.}{\left.\quad\left(1-\frac{x_{p}}{L}\right)\left(2-\frac{x_{p}}{L}\right) \frac{x_{p}}{L} \frac{x}{L}-\left(\frac{x}{L}\right)^{3}\right],} \\
x_{p}<x \leq L .
\end{array}\right.
\end{aligned}
$$

Considering the symmetry, four sections of the bridge are selected, and the comparison of (6) and (7) is plotted in Figure 2.

Figure 2 shows that they are almost the same. And the assumption of sine functions being thought as mode shapes is verified rational enough in another aspect:

$$
\varphi_{n}(x)=\sin \frac{n \pi x}{L} .
$$

2.2. A Simply Supported Girder Bridge Traversed by a Moving Sprung Mass. Due to neglect of the mass of the vehicle in the section above, coupled vibration in the vehicle-bridge system is not considered. To make a good comprehension of this effect, a simply supported girder bridge traversed by a moving sprung mass has been adopted in this section [29] (Figure 3).

In Figure 3, the moving vehicle has been simplified as a sprung mass, including the mass of vehicle body $m_{v}$ and the mass of the wheel $m_{t}$. The vehicle body and the wheel are connected with a spring and a damper. Also, it is assumed that the wheel is contacted with the bridge all the time. In 


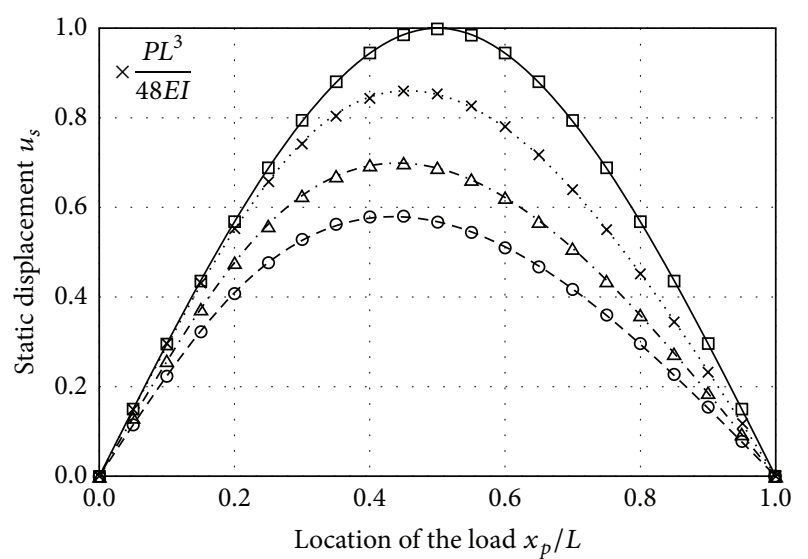

$L / 2 \operatorname{Eqn}(5)$

$\Delta \quad L / 4 \operatorname{Eqn}(5)$

$-L / 2 \operatorname{Eqn}(6)$

... $L / 4 \operatorname{Eqn}(6)$

$\times \quad L / 3 \operatorname{Eqn}(5)$

- $L / 5 \mathrm{Eqn}(5)$

.... $L / 3 \operatorname{Eqn}(6)$

-. $L / 5 \operatorname{Eqn}(6)$

FIgURE 2: Comparison of static displacement.

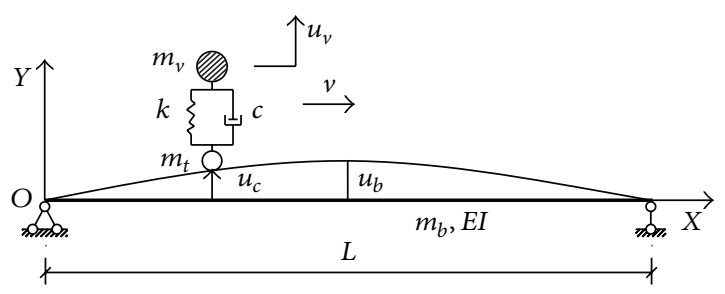

FIgURE 3: A moving sprung mass.

addition, the bridge is thought to be vibrated based on only the first mode shape. Likewise, there is no initial vibration of the bridge, and the damping of the bridge is ignored.
Respectively, based on the theory of structural dynamics, the governing equations of the vehicle body and the bridge can be given by

$$
\begin{gathered}
m_{v} \ddot{u}_{v}+c\left(\dot{u}_{v}-\dot{u}_{c}\right)+k\left(u_{v}-u_{c}\right)=0, \\
m^{*} \ddot{u}_{b}+k^{*} u_{b}=p^{*},
\end{gathered}
$$

where $u_{c}$ is the displacement of the contact point and $m^{*}, k^{*}$, and $p^{*}$ are, respectively, generalized mass, stiffness, and load of the bridge. And all of these parameters can be calculated by the following equations:

$$
\begin{gathered}
\varphi(x)=\sin \frac{\pi x}{L} \\
u_{c}(t)=u_{b}(t) \sin \frac{\pi v t}{L} \\
\dot{u}_{c}=\frac{\pi v}{L} u_{b} \cos \frac{\pi v t}{L}+\dot{u}_{b} \sin \frac{\pi v t}{L} \\
\ddot{u}_{c}=-\left(\frac{\pi v}{L}\right)^{2} u_{b} \sin \frac{\pi v t}{L}+2 \frac{\pi v}{L} \dot{u}_{b} \cos \frac{\pi v t}{L}+\ddot{u}_{b} \sin \frac{\pi v t}{L}, \\
m^{*}=\int_{0}^{L} m \varphi^{2}(x) d x=\frac{1}{2} m L \\
k^{*}=\int_{0}^{L} E I\left[\varphi^{\prime \prime}(x)\right]^{2} d x=\frac{\pi^{4} E I}{2 L^{3}}, \\
p^{*}=\int_{0}^{L} p \varphi(x) d x .
\end{gathered}
$$

Substituting ((10c) (10h)) into (9b) and combining (9a) and $(9 b)$, then

$$
\begin{aligned}
& {\left[\begin{array}{cc}
m_{v} & 0 \\
0 & \frac{m L}{2}+m_{t} \sin ^{2} \frac{\pi v t}{L}
\end{array}\right]\left\{\begin{array}{l}
\ddot{u}_{v} \\
\ddot{u}_{b}
\end{array}\right\}} \\
& +\left[\begin{array}{cc}
c & -c \sin \frac{\pi v t}{L} \\
-c \sin \frac{\pi v t}{L} & \frac{\pi v}{L} \sin \frac{\pi v t}{L}\left(c \sin \frac{\pi v t}{L}+2 m_{t} \cos \frac{\pi v t}{L}\right)
\end{array}\right]\left\{\begin{array}{l}
\dot{u}_{v} \\
\dot{u}_{b}
\end{array}\right\}
\end{aligned}
$$

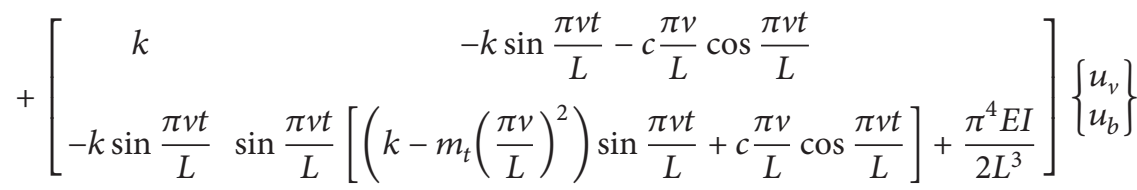

$$
\begin{aligned}
& =\left\{\begin{array}{c}
0 \\
\left.-\left(m_{t}+m_{v}\right) g \sin \frac{\pi v t}{L}\right\} .
\end{array}\right.
\end{aligned}
$$


In general, the mass of the wheel is much less than that of the vehicle body, so it can be ignored. And when the damping of the vehicle is neglected, (11) can be simplified as

$$
\begin{aligned}
& {\left[\begin{array}{cc}
m_{v} & 0 \\
0 & \frac{m L}{2}
\end{array}\right]\left\{\begin{array}{l}
\ddot{u}_{v} \\
\ddot{u}_{b}
\end{array}\right\}+\left[\begin{array}{cc}
k & -k \sin \frac{\pi v t}{L} \\
-k \sin \frac{\pi v t}{L} & k \sin ^{2} \frac{\pi v t}{L}+\frac{\pi^{4} E I}{2 L^{3}}
\end{array}\right]\left\{\begin{array}{l}
u_{v} \\
u_{b}
\end{array}\right\}} \\
& \quad=\left\{\begin{array}{c}
0 \\
\left.-\left(m_{t}+m_{v}\right) g \sin \frac{\pi v t}{L}\right\} .
\end{array}\right.
\end{aligned}
$$

Obviously, the fundamental frequency and the maximum static displacement of the vehicle and the bridge can be given by

$$
\begin{gathered}
\omega_{v}=\sqrt{\frac{k}{m_{v}}}, \\
\omega_{b}=\sqrt{\frac{k^{*}}{m^{*}}}, \\
u_{v s, \max }=\frac{m_{v} g}{k}, \\
u_{b s, \max }=\frac{m_{v} g}{k^{*}} .
\end{gathered}
$$

In accordance with the current codes, the dynamic load allowance (DLA, $\eta$ ) is defined as the ratio of the maximum dynamic response and the maximum static response. And the impact factor (IF, $\mu$ ) in the code of China (JTG D60-2004) is equal to DLA subtracted by one as follows:

$$
\begin{gathered}
\eta_{v}=\frac{u_{v}}{m_{v} g / k}=\frac{u_{v} \omega_{v}^{2}}{g}=1+\mu_{v}, \\
\eta_{b}=\frac{u_{b}}{m_{v} g / k^{*}}=\frac{u_{b} \omega_{b}^{2}}{2 \kappa g}=1+\mu_{b},
\end{gathered}
$$

where $\kappa$ is the ratio between the mass of the vehicle and that of the bridge. Besides, another two important nondimensional parameters are introduced here:

$$
\begin{gathered}
\kappa=\frac{m_{v}}{m_{b}}=\frac{m_{v}}{m L}, \\
\alpha=\frac{\omega_{d}}{\omega_{b}}=\frac{\pi v / L}{\omega_{b}}, \\
\gamma=\frac{\omega_{v}}{\omega_{b}} .
\end{gathered}
$$

Then (12) can be written as

$$
\left[\begin{array}{cc}
\frac{1}{\omega_{v}^{2}} & 0 \\
0 & \frac{2 \kappa \gamma^{4}}{\omega_{v}^{2}}
\end{array}\right]\left\{\begin{array}{l}
\ddot{\eta}_{v} \\
\ddot{\eta}_{b}
\end{array}\right\}
$$

$$
\begin{aligned}
& +\left[\begin{array}{cc}
1 & -2 \kappa \gamma^{2} \sin \frac{\alpha \omega_{v} t}{\gamma} \\
-2 \kappa \gamma^{2} \sin \frac{\alpha \omega_{v} t}{\gamma} & 4 \kappa^{2} \gamma^{4} \sin ^{2} \frac{\alpha \omega_{v} t}{\gamma}+2 \kappa \gamma^{2}
\end{array}\right]\left\{\begin{array}{l}
\eta_{v} \\
\eta_{b}
\end{array}\right\} \\
& =\left\{\begin{array}{c}
0 \\
\left.-2 \kappa \gamma^{2} \sin \frac{\alpha \omega_{\nu} t}{\gamma}\right\} .
\end{array}\right.
\end{aligned}
$$

It can be seen from (17) that the most significant parameters that influenced the IF or the DLA of the bridge are $\omega_{v}, \kappa$, $\alpha$, and $\gamma$.

Now, the influence of the natural frequency of the vehicle is discussed in detail. Equation (17) shows that the influence effect has two parts, including the term $1 / \omega_{v}^{2}$ in the mass matrix and the term $\omega_{v} t$ in the stiffness matrix. Obviously, when the natural frequency changes, due to the characteristics of the sine function, only the time corresponding to the maximum response has changed other than the maximum value itself. In addition, for fixed value of $\kappa, \alpha$, and $\gamma$, the maximum dynamic load allowance can be obtained. And then the corresponding accelerations are written as

$$
\begin{aligned}
& \ddot{u}_{b}=A \omega_{v}^{2} u_{b}, \\
& \ddot{u}_{v}=B \omega_{v}^{2} u_{v},
\end{aligned}
$$

where $A$ and $B$ are only dependent on the values of $\kappa, \alpha$, and $\gamma$, other than the frequency $\omega_{v}$. Then the first part of (17) is not related to the frequency, as the frequency has disappeared when the mass matrix is multiplied by the acceleration vector.

Totally, based on simplified model and derivation above, the most significant influence parameters may be $\kappa, \alpha$, and $\gamma$, defined in (16a) to (16c).

\section{Program for Vehicle-Bridge Coupled Vibration Analysis}

Based on their own advantages of existing generalized commercial software ANSYS and MATLAB, the program VBCVA (Vehicle-Bridge Coupled Vibration Analysis) has been developed by our own research group. It is used for vibration and dynamic analysis of the vehicle-bridge coupled system. Upon the modal synthesis method, the bridge model is found by ANSYS, while the vehicle model and the roughness model are established by MATLAB.

3.1. Bridge Equations. According to the theory of structural dynamics [30], the governing equation of the bridge can be given by

$$
\left[M_{b}\right]\left\{\ddot{U}_{b}\right\}+\left[C_{b}\right]\left\{\dot{U}_{b}\right\}+\left[K_{b}\right]\left\{U_{b}\right\}=\left\{F_{b}\right\}
$$

in which the $\left\{F_{b}\right\}$ denotes the load vector induced by the moving vehicles and $\left[M_{b}\right],\left[C_{b}\right]$, and $\left[K_{b}\right]$ denote, respectively, the mass matrix, damping matrix, and stiffness matrix. Furthermore, $\left\{U_{b}\right\}$ is the displacement of the bridge, the first derivative of the displacement is the vibration velocity, and 
the second derivative of the displacement is the vibration acceleration. It is worth noting that all these symbols and this equation are described in Cartesian coordinate system.

As there are various types of highway bridges and they are much more complicated with the increasing technology, the accurate modeling of the bridge may be difficult to realize by our own written program. In addition, this will hinder the generalization and the development of that program. And the limitation can be obviously seen when the equations of various types of bridges are different. Therefore, the modal synthesis method has been adopted. Another advantage of this translation is the reduction of the degree number:

$$
\left\{U_{b}\right\}=[\Phi]\left\{Z_{b}\right\}
$$

where $[\Phi]$ is the mode shape matrix of the bridge and $\left[Z_{b}\right]$ is the coordinate in the modal coordinate system, which denotes the contribution of every mode shapes.

Substituting (20) into (19), premultiplied by the transposed matrix of the mode shapes, the following equation is obtained:

$$
\left[M_{B}\right]\left\{\ddot{Z}_{b}\right\}+\left[C_{B}\right]\left\{\dot{Z}_{b}\right\}+\left[K_{B}\right]\left\{Z_{b}\right\}=\left\{F_{B}\right\}
$$

where $\left[M_{B}\right],\left[C_{B}\right],\left[K_{B}\right]$, and $\left\{F_{B}\right\}$ are mass matrix, damping matrix, stiffness matrix, and load vector in the modal coordinate system. They are given by

$$
\begin{gathered}
{\left[M_{B}\right]=[\Phi]^{T}\left[M_{b}\right][\Phi],} \\
{\left[C_{B}\right]=[\Phi]^{T}\left[C_{b}\right][\Phi],} \\
{\left[K_{B}\right]=[\Phi]^{T}\left[K_{b}\right][\Phi],} \\
{\left[F_{B}\right]=[\Phi]^{T}\left[F_{b}\right] .}
\end{gathered}
$$

For convenience in application, the matrix of mode shape obtained from ANSYS is normalized. Then the following matrixes are used in the program VBCVA:

$$
\begin{aligned}
& {\left[M_{B}\right]=\left[\begin{array}{ccc}
1 & \cdots & 0 \\
\vdots & \ddots & \vdots \\
0 & \cdots & 1
\end{array}\right],} \\
& {\left[C_{B}\right]=\left[\begin{array}{ccc}
2 \xi_{1} \omega_{1} & \cdots & 0 \\
\vdots & \ddots & \vdots \\
0 & \cdots & 2 \xi_{n} \omega_{n}
\end{array}\right],} \\
& {\left[K_{B}\right]=\left[\begin{array}{ccc}
\omega_{1}^{2} & \cdots & 0 \\
\vdots & \ddots & \vdots \\
0 & \cdots & \omega_{n}^{2}
\end{array}\right],}
\end{aligned}
$$

where $\xi_{n}$ and $\omega_{n}$ are the damping ratio and the natural frequency of the $n$th mode shape.

3.2. Vehicle Equations. Actually, the moving vehicle can be looked at as a vibration system with multidegrees of freedom. In this study, D'Alembert's principle is used for deducing dynamic equations of spatial vehicle models. And the position induced by the static weight of the vehicle is selected as the reference position [31].

The schematic plot of the vehicle model can be seen in Figure 4 . If the number of axles is $n$, the degree of freedom (dof) is $2 n+3$, including the vertical dof $Z_{s 1}$, pitching dof $Z_{s 2}$, swung dof $Z_{s 3}$ of the vehicle body, and the vertical dof of every wheels. It can be seen from the Figure 3 that

$$
\begin{gathered}
a_{i}=X_{G}-d_{i}, \quad i=1,2, \ldots n, \\
b_{i}=Y_{G}-w_{i}, \quad i=1,2
\end{gathered}
$$

in which $X_{G}$ and $Y_{G}$ are the coordinates of the centre-ofgravity of the vehicle and $a_{i}$ and $b_{i}$ denote, respectively, the distance from the wheel to the centre in longitudinal and transverse direction. Furthermore, $d_{i}$ is the distance from the wheel to the front axle in longitudinal direction, and $w_{i}$ is the wheel space.

There are some assumptions on the vehicle model. The wheel and the bridge will contact with each other all the time. Only vertical effects between the vehicle and the bridge are considered, while longitudinal and transverse effects are ignored. The vehicle body and all wheels are assumed as rigid bodies with corresponding mass, while the spring and the damper are linear [32].

Then the vehicle equation can be given by

$$
\left[M_{V}\right]\left\{\ddot{Z}_{V}\right\}+\left[C_{V}\right]\left\{\dot{Z}_{V}\right\}+\left[K_{V}\right]\left\{Z_{V}\right\}=\left\{F_{V}\right\}
$$

in which the $\left\{F_{V}\right\}$ denotes the load vector induced by the bridge and $\left[M_{V}\right],\left[C_{V}\right]$, and $\left[K_{V}\right]$ denote, respectively, the mass matrix, damping matrix, and stiffness matrix of the vehicle. Furthermore, $\left\{Z_{V}\right\}$ is the displacement of the vehicle, the first derivative of the displacement is the vibration velocity, and the second derivative of the displacement is the vibration acceleration. They are listed as follows. It has to be noted that the stiffness matrix $\left[K_{V}\right]$ is just similar with the damping matrix $\left[C_{V}\right]$, replacing the symbol $c$ with the symbol $k$ :

$$
\begin{gathered}
{\left[M_{V}\right]=\operatorname{diag}\left\{m_{s}, J_{y}, J_{x}, m_{t 1}, m_{t 2}, \ldots, m_{t 2 n}\right\},} \\
\left\{Z_{V}\right\}=\left\{Z_{s 1}, Z_{s 2}, Z_{s 3}, Z_{t 1}, Z_{t 2}, \ldots, Z_{t 2 n}\right\}^{T}=\left\{\begin{array}{c}
\left\{Z_{s}\right\} \\
\left\{Z_{t}\right\}
\end{array}\right\},
\end{gathered}
$$




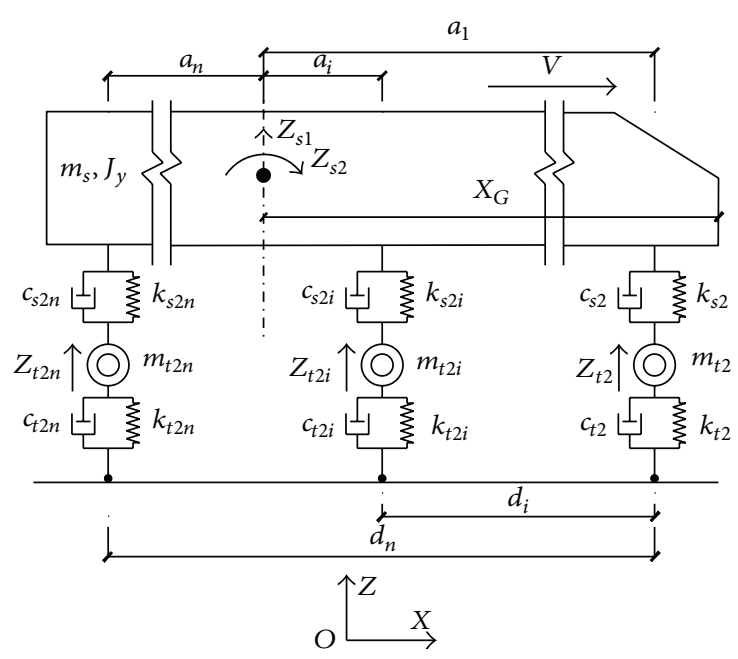

(a) Elevation view

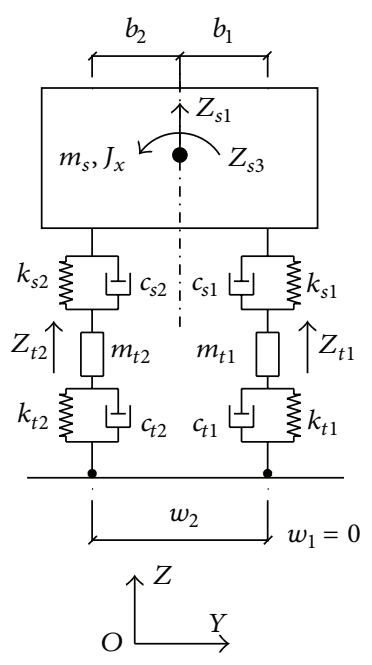

(b) Front view

FIgURE 4: Schematic plot of the vehicle model.

$$
\begin{aligned}
& \left\{F_{V}\right\}=\left\{0,0,0, k_{t 1} \Delta_{1}+c_{t 1} \dot{\Delta}_{1}, k_{t 2} \Delta_{2}+c_{t 2} \dot{\Delta}_{2}, \ldots, k_{t 2 n} \Delta_{2 n}+c_{t 2 n} \dot{\Delta}_{2 n}\right\}^{T} \text {, } \\
& {\left[C_{V}\right]=\left[\begin{array}{ll}
C_{V 11} & C_{V 12} \\
C_{V 21} & C_{V 22}
\end{array}\right] \text {, }} \\
& {\left[C_{V 11}\right]=\left[\begin{array}{ccc}
\sum_{i=1}^{n} c_{s 2 i-1}+c_{s 2 i} & -\sum_{i=1}^{n} a_{i}\left(c_{s 2 i-1}+c_{s 2 i}\right) & -\sum_{i=1}^{n}\left(b_{1} c_{s 2 i-1}+b_{2} c_{s 2 i}\right) \\
-\sum_{i=1}^{n} a_{i}\left(c_{s 2 i-1}+c_{s 2 i}\right) & \sum_{i=1}^{n} a_{i}^{2}\left(c_{s 2 i-1}+c_{s 2 i}\right) & -\sum_{i=1}^{n}\left(b_{1} a_{i} c_{s 2 i-1}+b_{2} a_{i} c_{s 2 i}\right) \\
-\sum_{i=1}^{n}\left(b_{1} c_{s 2 i-1}+b_{2} c_{s 2 i}\right) & -\sum_{i=1}^{n}\left(b_{1} a_{i} c_{s 2 i-1}+b_{2} a_{i} c_{s 2 i}\right) & \sum_{i=1}^{n}\left(b_{1}^{2} c_{s 2 i-1}+b_{2}^{2} c_{s 2 i}\right)
\end{array}\right],} \\
& {\left[C_{V 12}\right]=\left[\begin{array}{cccc}
-c_{s 1} & -c_{s 2} & \cdots & -c_{s 2 n} \\
a_{1} c_{s 1} & a_{1} c_{s 2} & \cdots & a_{n} c_{s 2 n} \\
-b_{1} c_{s 1} & -b_{2} c_{s 2} & \cdots & -b_{2} c_{s 2 n}
\end{array}\right] \text {, }} \\
& {\left[C_{V 21}\right]=\left[\begin{array}{ccc}
-c_{s 1} & a_{1} c_{s 1} & -b_{1} c_{s 1} \\
-c_{s 2} & a_{1} c_{s 2} & -b_{2} c_{s 2} \\
\vdots & \vdots & \vdots \\
-c_{s 2 n} & a_{n} c_{s 2 n} & -b_{1} c_{s 2 n}
\end{array}\right]} \\
& {\left[C_{V 22}\right]=\left[\begin{array}{cccc}
c_{s 1}+c_{t 1} & 0 & \cdots & 0 \\
0 & c_{s 2}+c_{t 2} & \cdots & 0 \\
\vdots & \vdots & \ddots & \vdots \\
0 & 0 & \cdots & c_{s 2 n}+c_{t 2 n}
\end{array}\right] \text {. }}
\end{aligned}
$$

3.3. Coupled Equations. The interaction force between the bridge and the vehicle can be considered from two aspects. One is the force of the vehicle $F_{t i}$ induced by the vibration of the bridge, and the other one is the force of the bridge
$F_{b i}$ caused by the vehicle, including the static weight and the dynamic force:

$$
\begin{gathered}
F_{t i}=-k_{t i} \Delta_{i}-c_{t i} \dot{\Delta}_{i}, \\
F_{b i}=F_{G i}-F_{t i},
\end{gathered}
$$


where $F_{G i}$ denotes the sum of two parts, the first part is the gravity of the $i$ th wheel itself, and the other part is the distribution of the weight of the vehicle body on the $i$ th wheel. And $\Delta_{i}$ is the relative displacement of the contact point between the $i$ th wheel and the bridge. Also, the first derivative of the displacement is the vibration velocity. They can be obtained by

$$
\begin{gathered}
\Delta_{i}=Z_{t i}(t)-U_{b i}(x, t)-r_{i}(x), \\
\dot{\Delta}_{i}=\dot{Z}_{t i}-U_{b i}^{\prime} \dot{x}-\dot{U}_{b i}-r_{i}^{\prime} \dot{x}=\dot{Z}_{t i}-U_{b i}^{\prime} V-\dot{U}_{b i}-r_{i}^{\prime} V
\end{gathered}
$$

in which the $Z_{t i}$ denotes the vertical displacement of the $i$ th wheel and $U_{b i}$ and $U_{b i}^{\prime}$ denote, respectively, the vertical displacement and the rotation of the bridge at the location of the contact point. And, $r_{i}$ is the vertical roughness, and $V$ is the speed of the moving vehicle.

Coupled equations of the vehicle-bridge vibration system can be obtained by the combination of the bridge equation and the vehicle equation above. They are listed as follows:

$$
\left[\begin{array}{ccc}
{\left[M_{v s}\right]_{n s \times n s}} & {\left[M_{v s t}\right]_{n s \times n t}} & {[0]_{n s \times n m}} \\
{\left[M_{v t s}\right]_{n t \times n s}} & {\left[M_{v t}\right]_{n t \times n t}} & {[0]_{n t \times n m}} \\
{[0]_{n m \times n s}} & {[0]_{n m \times n t}} & {\left[M_{B}\right]_{n m \times n m}}
\end{array}\right]\left\{\begin{array}{c}
\left\{\ddot{Z}_{s}\right\}_{n s} \\
\left\{\ddot{Z}_{t}\right\}_{n t} \\
\left\{\ddot{Z}_{b}\right\}_{n m}
\end{array}\right\}
$$

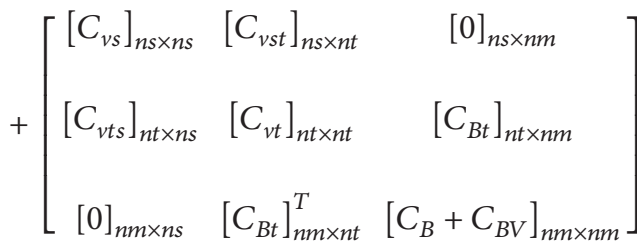

$\times\left\{\begin{array}{c}\left\{\dot{Z}_{s}\right\}_{n s} \\ \left\{\dot{Z}_{t}\right\}_{n t} \\ \left\{\dot{Z}_{b}\right\}_{n m}\end{array}\right\}$

$+\left[\begin{array}{ccc}{\left[K_{v s}\right]_{n s \times n s}} & {\left[K_{v s t}\right]_{n s \times n t}} & {[0]_{n s \times n m}} \\ {\left[K_{v t s}\right]_{n t \times n s}} & {\left[K_{v t}\right]_{n t \times n t}} & {\left[K_{B t 2}\right]_{n t \times n m}} \\ {[0]_{n m \times n s}} & {\left[K_{B t 1}\right]_{n m \times n t}} & {\left[K_{B}+K_{B V}\right]_{n m \times n m}}\end{array}\right]$

$\times\left\{\begin{array}{c}\left\{Z_{s}\right\}_{n s} \\ \left\{Z_{t}\right\}_{n t} \\ \left\{Z_{b}\right\}_{n m}\end{array}\right\}$

$=\{F\}_{n v+n m}$,

$$
\begin{gathered}
{\left[C_{B}+C_{B V}\right]=\left[\begin{array}{ccccc}
C_{1}+\sum_{i=n}^{m} \phi_{1}^{(i)} c_{t i} \phi_{1}^{(i)} & \sum_{i=n}^{m} \phi_{1}^{(i)} c_{t i} \phi_{2}^{(i)} & \cdots & \sum_{i=n}^{m} \phi_{1}^{(i)} c_{t i} \phi_{n m}^{(i)} \\
\sum_{i=n}^{m} \phi_{2}^{(i)} c_{t i} \phi_{1}^{(i)} & C_{2}+\sum_{i=n}^{m} \phi_{2}^{(i)} c_{t i} \phi_{2}^{(i)} & \cdots & \sum_{i=n}^{m} \phi_{2}^{(i)} c_{t i} \phi_{n m}^{(i)} \\
\vdots & \vdots & \ddots & \vdots \\
\sum_{i=n}^{m} \phi_{n m}^{(i)} c_{t i} \phi_{1}^{(i)} & \sum_{i=n}^{m} \phi_{n m}^{(i)} c_{t i} \phi_{2}^{(i)} & \cdots & C_{n m}+\sum_{i=n}^{m} \phi_{n m}^{(i)} c_{t i} \phi_{n m}^{(i)}
\end{array}\right],} \\
{\left[K_{B t 1}\right]=-\left[\begin{array}{ccccc}
k_{t 1} \phi_{1}^{(1)} & k_{t 2} \phi_{1}^{(2)} & \cdots & k_{t n t} \phi_{1}^{(n t)} \\
k_{t 1} \phi_{2}^{(1)} & k_{t 2} \phi_{2}^{(2)} & \cdots & k_{t n t} \phi_{2}^{(n t)} \\
\vdots & \vdots & \ddots & \vdots \\
k_{t 1} \phi_{n m}^{(1)} & k_{t 2} \phi_{n m}^{(2)} & \cdots & k_{t n t} \phi_{n m}^{(n t)}
\end{array}\right]} \\
{\left[K_{B t 2}\right]=\left[\begin{array}{ccccc}
c_{t 1} \phi_{1}^{\prime(1)} & c_{t 1} \phi_{2}^{\prime(1)} & \cdots & c_{t 1} \phi_{n m}^{\prime(1)} \\
c_{t 2} \phi_{1}^{\prime(2)} & c_{t 2} \phi_{2}^{\prime(2)} & \cdots & c_{t 2} \phi_{n m}^{\prime(2)} \\
\vdots & \vdots & \ddots & \vdots \\
c_{t n t} \phi_{1}^{\prime(n t)} & c_{t n t} \phi_{2}^{\prime(1)} & \cdots & c_{t n t} \phi_{n m}^{\prime(n t)}
\end{array}\right]}
\end{gathered}
$$




$$
=-\left[\begin{array}{cccc}
k_{t 1} \phi_{1}^{(1)}+V c_{t 1} \phi_{1}^{\prime(1)} & k_{t 2} \phi_{1}^{(2)}+V c_{t 1} \phi_{2}^{(1)} & \cdots & k_{t n t} \phi_{1}^{(n t)}+V c_{t 1} \phi_{n m}^{(1)} \\
k_{t 1} \phi_{2}^{(1)}+V c_{t 2} \phi_{1}^{\prime(2)} & k_{t 2} \phi_{2}^{(2)}+V c_{t 2} \phi_{2}^{\prime(2)} & \cdots & k_{t n t} \phi_{2}^{(n t)}+V c_{t 2} \phi_{n m}^{\prime(2)} \\
\vdots & \vdots & \ddots & \vdots \\
k_{t 1} \phi_{n m}^{(1)}+V c_{t n t} \phi_{1}^{\prime(n t)} & k_{t 2} \phi_{n m}^{(2)}+V c_{t n t} \phi_{2}^{\prime(1)} & \cdots & k_{t n t} \phi_{n m}^{(n t)}+V c_{t n t} \phi_{n m}^{\prime(n t)}
\end{array}\right],
$$$$
\left[K_{B}+K_{B V}\right]
$$

$$
=\left[\begin{array}{ccc}
K_{1}+\sum_{i=n}^{m} \phi_{1}^{(i)}\left(k_{t i} \phi_{1}^{(i)}+V c_{t i} \phi_{1}^{\prime(i)}\right) & \cdots & \sum_{i=n}^{m} \phi_{1}^{(i)}\left(k_{t i} \phi_{n m}^{(i)}+V c_{t i} \phi_{n m}^{\prime(i)}\right) \\
\vdots & \ddots & \vdots \\
\sum_{i=n}^{m} \phi_{n m}^{(i)}\left(k_{t i} \phi_{1}^{(i)}+V c_{t i} \phi_{1}^{\prime(i)}\right) & \cdots & K_{n m}+\sum_{i=n}^{m} \phi_{n m}^{(i)}\left(k_{t i} \phi_{n m}^{(i)}+V c_{t i} \phi_{n m}^{\prime(i)}\right)
\end{array}\right],
$$

$$
\{F\}=\left[\begin{array}{c}
\{0\}_{n s} \\
k_{t 1} r_{1}+V c_{t 1} r^{\prime} \\
\vdots \\
k_{t n t} r_{n t}+V c_{t n t} r_{n t}^{\prime} \\
-\sum_{i=n}^{m} \phi_{1}^{(i)}\left[\left(m_{s i}+m_{t i}\right) g+k_{t i} r_{i}+V c_{t i} r_{i}^{\prime}\right] \\
-\sum_{i=n}^{m} \phi_{2}^{(i)}\left[\left(m_{s i}+m_{t i}\right) g+k_{t i} r_{i}+V c_{t i} r_{i}^{\prime}\right] \\
\vdots \\
-\sum_{i=n}^{m} \phi_{n m}^{(i)}\left[\left(m_{s i}+m_{t i}\right) g+k_{t i} r_{i}+V c_{t i} r_{i}^{\prime}\right]
\end{array}\right]
$$

where the $m n$ denotes the number of selected mode shapes and $n v, n s$, and $n t$ denote, respectively, the total number of dof of all vehicles, the number of dof of the vehicle body of all vehicles, and the number of dof of all wheels. Other symbols are the same as before.

3.4. Solution of Coupled Equations. When a vehicle goes across the bridge, the position of the contact point changes with time. Therefore, the coupled equations are time-varying system of differential equations. And it is difficult to obtain the closed-form solutions. But they can be solved by some numerical methods, such as the central difference method, Newmark method, Wilson- $\theta$ method, and so on [33-35]. Wilson- $\theta$ method has been adopted in this study. It is a self-stabilization method, which is independent on the integration step and the shortest period $[36,37]$. And it also can be looked at as the modified linear acceleration method.

It is assumed that the acceleration during the period $\left[t_{i}\right.$, $\left.t_{i}+\theta \Delta t\right]$ is linearly varied. Firstly, the vibration of the system at the time of $t_{i}+\theta \Delta t$ is calculated based on the linear acceleration method, and then the vibration of the system at the time of $t i+\Delta t$ is deduced using the interpolation formula. And it is worth noting that this method has been verified unconditionally stable if the parameter $\theta$ is larger than 1.37 .
Based on the assumption of linear acceleration, the acceleration during this period $\left[t_{i}, t_{i}+\theta \Delta t\right]$ is given by

$$
\ddot{u}\left(t_{i}+\tau\right)=\ddot{u}\left(t_{i}\right)+\frac{\tau}{\theta \Delta t}\left[\ddot{u}\left(t_{i}+\theta \Delta t\right)-\ddot{u}\left(t_{i}\right)\right] .
$$

According to the integration, the vibration velocity and the dynamic displacement can be shown as follows:

$$
\begin{aligned}
\dot{u}\left(t_{i}+\tau\right)= & \dot{u}\left(t_{i}\right)+\tau \ddot{u}\left(t_{i}\right)+\frac{\tau^{2}}{2 \theta \Delta t}\left[\ddot{u}\left(t_{i}+\theta \Delta t\right)-\ddot{u}\left(t_{i}\right)\right], \\
u\left(t_{i}+\tau\right)= & u\left(t_{i}\right)+\tau \dot{u}\left(t_{i}\right) \\
& +\frac{1}{2} \tau^{2} \ddot{u}\left(t_{i}\right)+\frac{\tau^{3}}{6 \theta \Delta t}\left[\ddot{u}\left(t_{i}+\theta \Delta t\right)-\ddot{u}\left(t_{i}\right)\right] .
\end{aligned}
$$

When the time $\tau$ is equal to $\theta \Delta t$, the corresponding vibration velocity and the dynamic displacement are

$$
\begin{aligned}
\dot{u}\left(t_{i}+\theta \Delta t\right)= & \dot{u}\left(t_{i}\right)+\theta \Delta t \ddot{u}\left(t_{i}\right) \\
& +\frac{\theta \Delta t}{2}\left[\ddot{u}\left(t_{i}+\theta \Delta t\right)-\ddot{u}\left(t_{i}\right)\right],
\end{aligned}
$$




$$
\begin{aligned}
u\left(t_{i}+\theta \Delta t\right)= & u\left(t_{i}\right)+\theta \Delta t \dot{u}\left(t_{i}\right) \\
& +\frac{(\theta \Delta t)^{2}}{6}\left[\ddot{u}\left(t_{i}+\theta \Delta t\right)+2 \ddot{u}\left(t_{i}\right)\right] .
\end{aligned}
$$

To solve (32a) and (32b), the acceleration and the dynamic displacement at the time of $t_{i}+\theta \Delta t$ can be listed as follows:

$$
\begin{aligned}
\ddot{u}\left(t_{i}+\theta \Delta t\right)= & \frac{6}{(\theta \Delta t)^{2}}\left[u\left(t_{i}+\theta \Delta t\right)-u\left(t_{i}\right)\right] \\
& -\frac{6}{\theta \Delta t} \dot{u}\left(t_{i}\right)-2 \ddot{u}\left(t_{i}\right), \\
\dot{u}\left(t_{i}+\theta \Delta t\right)= & \frac{3}{\theta \Delta t}\left[u\left(t_{i}+\theta \Delta t\right)-u\left(t_{i}\right)\right] \\
& -2 \dot{u}\left(t_{i}\right)-\frac{\theta \Delta t}{2} \ddot{u}\left(t_{i}\right) .
\end{aligned}
$$

Of course, at the time of $t_{i}+\theta \Delta t$, the following vibration equation of the system should be satisfied:

$$
m \ddot{u}\left(t_{i}+\theta \Delta t\right)+c \dot{u}\left(t_{i}+\theta \Delta t\right)+k u\left(t_{i}+\theta \Delta t\right)=P\left(t_{i}+\theta \Delta t\right)
$$

in which the load vector $P\left(t_{i}+\theta \Delta t\right)$ can be obtained by the method of linear extrapolation:

$$
P\left(t_{i}+\theta \Delta t\right)=P\left(t_{i}\right)+\theta\left[P\left(t_{i}+\Delta t\right)-P\left(t_{i}\right)\right] .
$$

Substituting (33a), (33b), and (35) into (34) and rearranging, the following equation is obtained:

$$
\bar{k} u\left(t_{i}+\theta \Delta t\right)=\bar{P}\left(t_{i}+\theta \Delta t\right)
$$

where

$$
\begin{aligned}
\bar{k} & =k+\frac{6}{(\theta \Delta t)^{2}} m+\frac{3}{\theta \Delta t} c \\
\bar{P}\left(t_{i}+\theta \Delta t\right)= & P_{i}+\theta\left(P_{i+1}-P_{i}\right) \\
+ & {\left[\frac{6}{(\theta \Delta t)^{2}} u\left(t_{i}\right)+\frac{6}{\theta \Delta t} \dot{u}\left(t_{i}\right)+2 \ddot{u}\left(t_{i}\right)\right] m } \\
+ & {\left[\frac{3}{\theta \Delta t} u\left(t_{i}\right)+2 \dot{u}\left(t_{i}\right)+\frac{\theta \Delta t}{2} \ddot{u}\left(t_{i}\right)\right] c . }
\end{aligned}
$$

According to solving (36), the dynamic displacement at the time of $t_{i}+\theta \Delta t\left(u\left(t_{i}+\theta \Delta t\right)\right)$ can be known. Substituting $u\left(t_{i}+\theta \Delta t\right)$ into (33a), the acceleration at the time of $t_{i}+\theta \Delta t$ can be obtained. Then substituting it into (31a) and using the designation $\tau=\Delta t$, the acceleration at the time of $t_{i}+\Delta t$ is gained as

$$
\begin{aligned}
\ddot{u}\left(t_{i}+\Delta t\right)= & \frac{6}{\theta^{3}(\Delta t)^{2}}\left[u\left(t_{i}+\theta \Delta t\right)-u\left(t_{i}\right)\right] \\
& -\frac{6}{\theta^{2} \Delta t} \dot{u}\left(t_{i}\right)+\left(1-\frac{3}{\theta}\right) \ddot{u}\left(t_{i}\right) .
\end{aligned}
$$

Similarly, using the designations $\theta=1$ and $\tau=\Delta t$, the vibration velocity and the dynamic displacement at the time of $t_{i}+\Delta t$ are listed as follows:

$$
\begin{gathered}
\dot{u}\left(t_{i}+\Delta t\right)=\dot{u}\left(t_{i}\right)+\frac{\Delta t}{2}\left[\ddot{u}\left(t_{i}+\Delta t\right)+\ddot{u}\left(t_{i}\right)\right], \\
u\left(t_{i}+\Delta t\right)=u\left(t_{i}\right)+\Delta t \dot{u}\left(t_{i}\right)+\frac{(\Delta t)^{2}}{6}\left[\ddot{u}\left(t_{i}+\Delta t\right)+2 \ddot{u}\left(t_{i}\right)\right] .
\end{gathered}
$$

3.5. Roughness Model. In both design and evaluation, pavement roughness is the primary factor affecting the dynamic performances of the bridge traversed by the designated vehicles [38]. And, in the dynamic responses analysis of highway bridges under moving vehicles, it is considered to be a cause of vehicle vibration [39]. Deng and Cai have proposed that, due to the road surface deterioration of existing bridges, the calculated impact factors form field measurements could be higher than the values specified in design codes that mainly target new bridge design [15]. So it is necessary to include the pavement roughness in our own program.

There are two methods to take the roughness into account, field measurement and numerical simulation. As for the former way, it is measured generally by one of the following two methods, that is, (1) by using a profilometer or (2) by calculating pavement roughness backwards from vibration data of the well-researched dynamic properties of the vehicle [36]. Nowadays, based on much data from the field measurement, more researchers begin to admit the fact that the roughness is a realization of a random process that can be described by a power spectral density (PSD) function. And the pavement roughness model proposed by Hwang and Nowak [40] has been adopted in this study.

Typical PSD function can be approximated by an exponential function:

$$
S(\gamma)=\alpha \gamma^{-\beta} \quad \gamma_{L}<\gamma<\gamma_{U}
$$

in which the $\alpha$ denotes roughness coefficient and $\gamma, \gamma_{L}, \gamma_{U}$, and $\beta$ denote, respectively, spatial frequency $\left(\mathrm{m}^{-1}\right)$, lower limit, upper limit, and spectral shape index. It is assumed that the pavement roughness can be modeled as a stationary Gaussian random process. Therefore, it can be generated by an inverse Fourier transform:

$$
X(t)=\sum_{i=1}^{N} \sqrt{4 S\left(\gamma_{i}\right) \Delta \gamma} \cos \left(\gamma_{i} t-\theta_{i}\right),
$$

where $S\left(\gamma_{i}\right)$ is PSD function and $\theta_{i}$ is random number uniformly distributed from 0 to $2 \pi$. follows:

The process of generating pavement roughness is listed as

$$
\begin{gathered}
\Delta \gamma=\frac{\gamma_{U}-\gamma_{L}}{N}, \\
\gamma_{k}=\gamma_{L}+(k-0.5) \Delta \gamma \quad k=1,2, \ldots, N,
\end{gathered}
$$




$$
\begin{gathered}
S\left(\gamma_{k}\right)=\alpha \gamma_{k}^{-\beta}, \\
a_{k}^{2}=4 S\left(\gamma_{k}\right) \Delta \gamma, \\
h(x)=\sum_{k=1}^{N} a_{k} \cos \left(2 \pi \gamma_{k} x-\theta_{k}\right)
\end{gathered}
$$

in which the $x$ denotes the position in the longitudinal direction of the bridge, $h(x)$ is the roughness, and $N$ is the sampling number.

Considering common seen speeds of vehicles in highway bridges, the lower and upper limits of the spatial frequency are specified as $0.05 \mathrm{~m}^{-1}$ and $3.00 \mathrm{~m}^{-1}$ [7]. Furthermore, $N$ is usually equal to 512 , and the spectral shape index $\beta$ is 2 in general. Also, the selected value of the roughness coefficient $\alpha$ can be seen in Table 1 .

As for different conditions, five typical pavement roughness examples are obtained using the program VBCVA. And the results are plotted in Figure 5.

In addition, the relation between the maximum amplitude of the roughness sample and the roughness coefficient is studied. It can be seen from Figure 6 that they are square relation, which is consistent with ((41a), (41b), (41c), (41d), and (41e)).

3.6. Flowchart of the Program. Due to various types of bridges, the modal synthesis method is adopted in the program VBCVA for general use. At first, the dynamic characteristics of the highway bridge, including natural frequencies and mode shapes, are obtained based on the finite element model (FEM) built by the commercial software ANSYS. Meanwhile, the data files for vehicles are prepared by another commercial software MATLAB. Then the coupled equations are calculated using the Wilson- $\theta$ method [41]. It is developed following the flowchart in Figure 7.

To supplement the application of this program, it is necessary to emphasize that the data files preparation includes bridge data (frequencies, mode shapes, damping ratios, and coordinates of nodes), pavement roughness model, and vehicle data (vehicle type, speed, number, and initial location). Also, controlling parameters mainly means $\theta$ in the method of Wilson- $\theta$ and the integration step. After all calculations, the postprocessing is done by MATLAB, including plots of dynamic responses of the designated degree of the bridge or vehicles.

The program can be used for calculating the cases of multilanes and multivehicles (both in longitudinal direction and in transverse direction). Also, the number of axles or vehicles is not limited. Furthermore, the validity and the rationality have been verified by some numerical and experimental results from the existing papers [42]. Therefore, this program has to be thought of as convenient and powerful enough for the analysis of the vehicle-bridge coupled vibration problem.

\section{Numerical Simulations Based on the Orthogonal Experimental Design}

Concerning dynamic responses of highway bridges to moving vehicular loads, three methods are commonly adopted,
TABLE 1: Roughness coefficient $\alpha$.

\begin{tabular}{lc}
\hline Condition & Roughness coefficient $\alpha$ \\
\hline Very good & $\alpha<0.24 \times 10^{-6}$ \\
Good & $0.24 \times 10^{-6}<\alpha \leq 1.0 \times 10^{-6}$ \\
Average & $1.0 \times 10^{-6}<\alpha \leq 4.0 \times 10^{-6}$ \\
Poor & $4.0 \times 10^{-6}<\alpha \leq 16.0 \times 10^{-6}$ \\
Very poor & $\alpha>16.0 \times 10^{-6}$ \\
\hline
\end{tabular}

including theoretical derivation, dynamic loading test, and numerical simulations. As we know, the first method can only be appropriate for some simplified models, while the last two methods can be applied to the actual situation in general. However, due to the economy and many other causes, most of studies focused on dynamic responses induced by much fewer factors. In addition, influence of interactions between these factors on dynamic responses is barely studied. Therefore, based on orthogonal experimental design, influences of many factors and their interactions on the dynamic responses of simply supported girder bridges to moving vehicular loads are discussed at length in this section.

4.1. Orthogonal Experimental Design. As for the multifactor experimental problem, the full factorial design was widely accepted in the early stage. There are two primary benefits of this method. Firstly, it reveals whether the effect of each factor depends on the levels of other factors in the experiment. And one factorial experiment can show "interaction effects" that a series of experiments each involving a single factor cannot. Secondly, it provides excellent precision for the regression model parameter estimates that summarize the combined effects of the factors [43].

However, when the variables are more, the size of the full factorial design is much extremely larger. For example, with three levels of every factor, increasing the number of factors from 2 to 4 increases the size of the full factorial design from $3^{2}$ to $3^{4}, 9$ times larger. So fractional factorial designs have come out to largely reduce the work in the analysis of multifactor problem. In statistics, fractional factorial designs consist of a carefully chosen subset of the experimental runs of a full factorial design. That is chosen so as to exploit the sparsity-of-effects principle to expose information about the most important features of the problem studied, while using a fraction of the effort of a full factorial design in terms of experimental runs.

Obviously, there are two principal contradictions in the fractional factorial design. One is the contradiction between the larger runs in the full factorial design and the expected smaller runs in actual operation. The other one is that between the smaller runs and the expected whole information, which is just the same as that obtained from the full factorial design [44]. To solve these two contradictions, the orthogonal experimental design is one of the best methods. According to a more rational arrangement, such as the orthogonal array, a minority of runs that are most typical can be selected, which can solve the first contradiction. Using some scientific methods of data processing, including the 


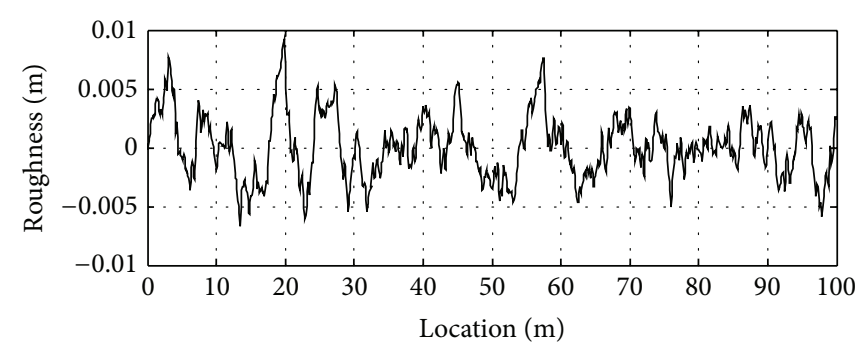

(a) Very good $\left(\alpha=0.20 \times 10^{-6}\right)$

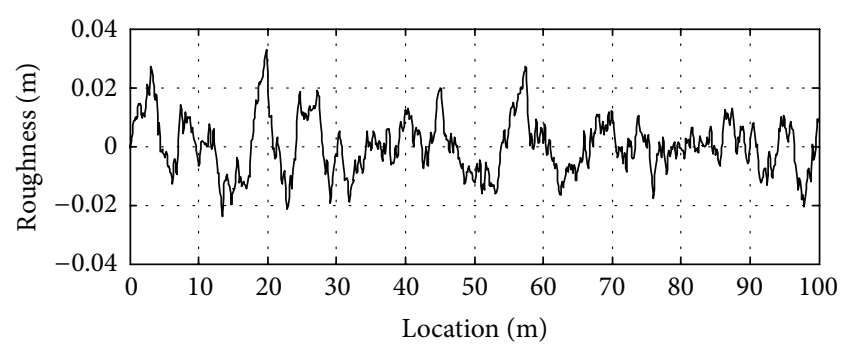

(c) Average $\left(\alpha=2.50 \times 10^{-6}\right)$

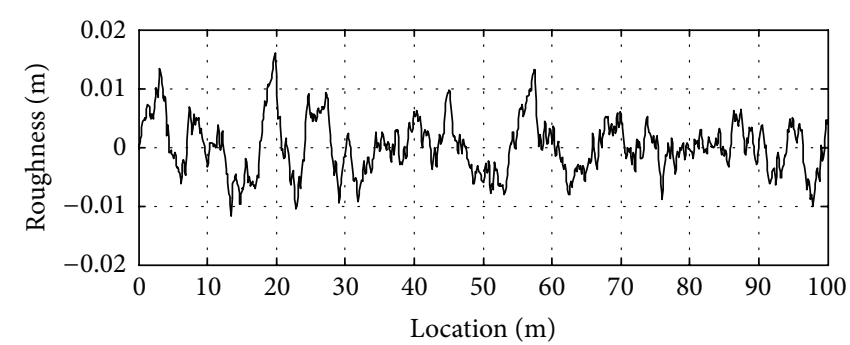

(b) $\operatorname{Good}\left(\alpha=0.60 \times 10^{-6}\right)$

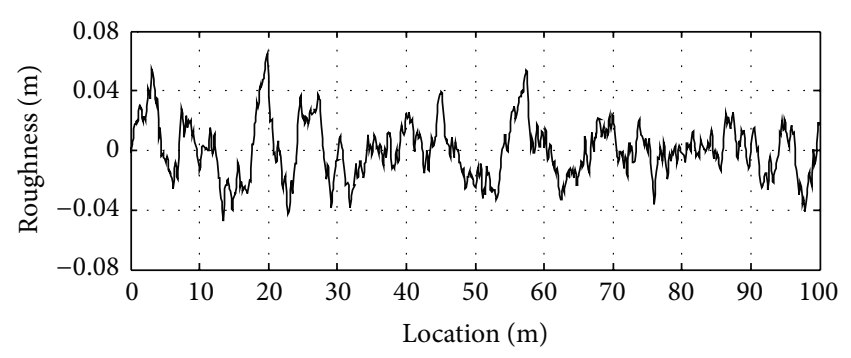

(d) Poor $\left(\alpha=10.0 \times 10^{-6}\right)$

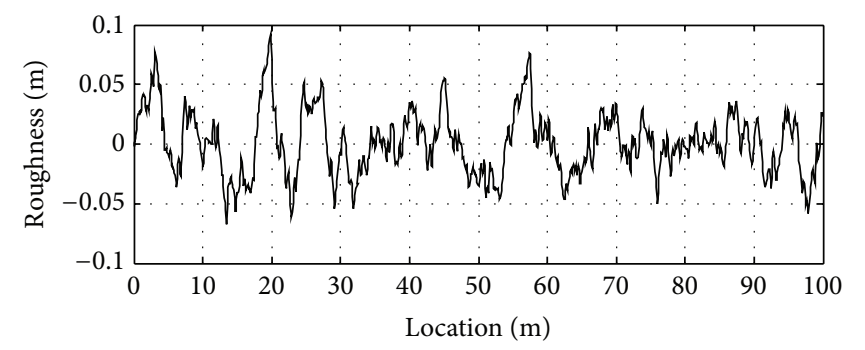

(e) Very poor $\left(\alpha=20.0 \times 10^{-6}\right)$

FIGURE 5: Five pavement roughness examples.

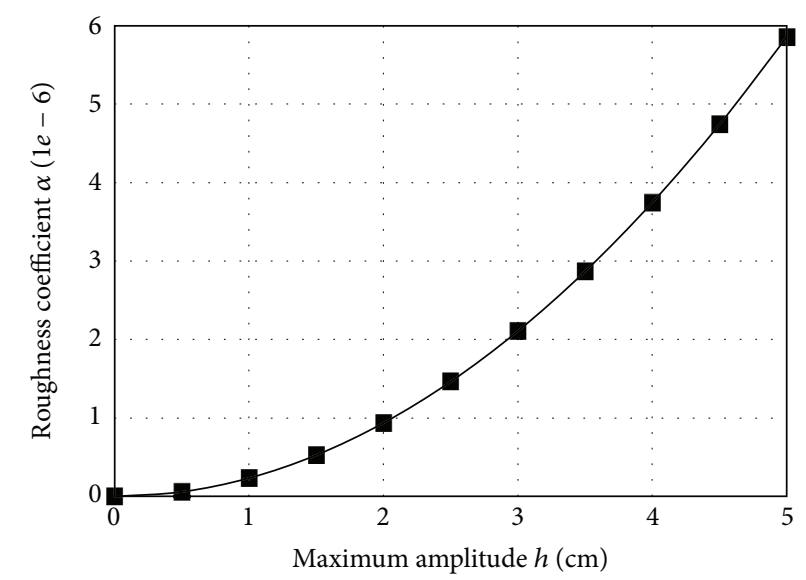

FIGURE 6: Relation analysis of roughness.

range analysis and the variance analysis, many reasonable conclusions can be obtained based on the minority of experiments, which can solve the second contradiction. In a word, the orthogonal experimental design has been verified as a good method.
The orthogonal array is the basis of the orthogonal experimental design. And it has been constructed based on these two mathematical courses, combinatorics and probability. Of course, it is not necessary for engineers to know how to construct it. We only need to transplant existing orthogonal 


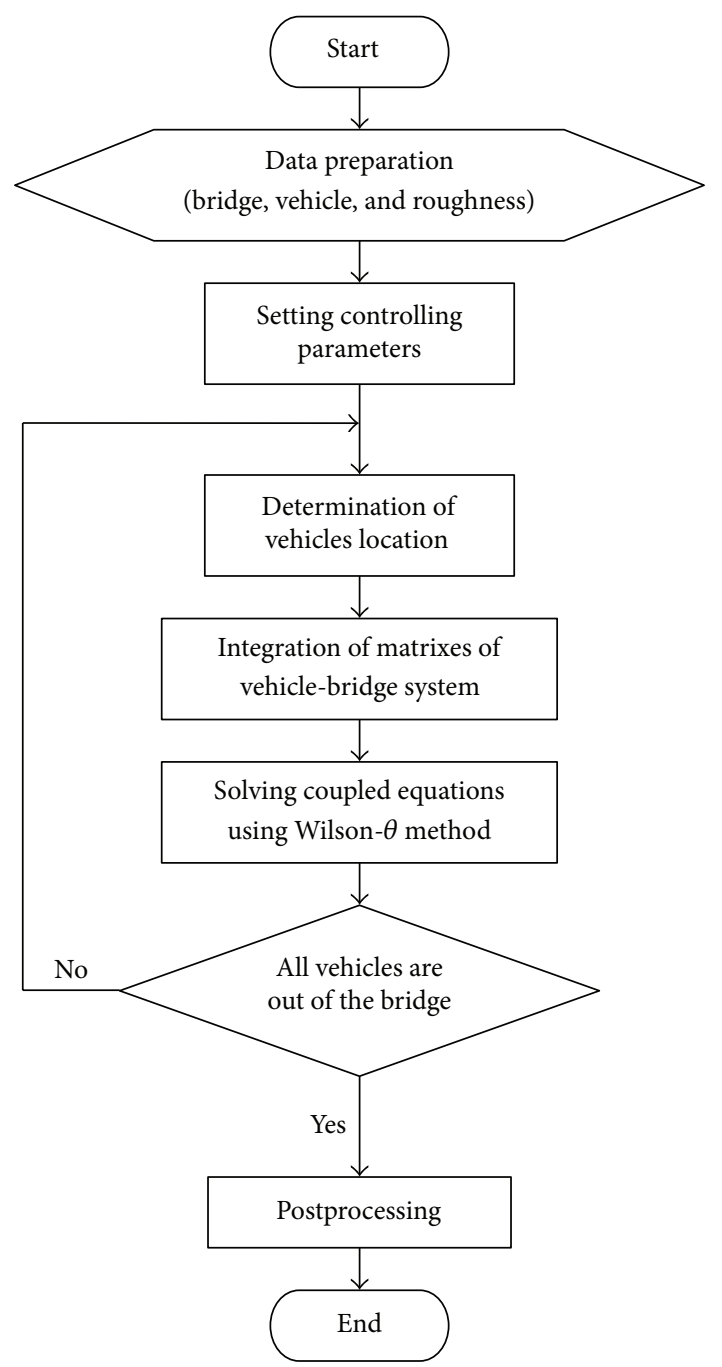

FIgURE 7: Flowchart of the program VBCVA.

arrays into engineering areas. The orthogonal array is usually denoted by $L_{a}\left(b^{c}\right)$, in which $L$ is the code of orthogonal array, $a$ is the number of experimental runs, $b$ is the number of levels, and $c$ is the number of factors. In the recent period, this type of construction thought has become widespread.

It has been proved that the "interaction effects" are always seen in the multifactor experiment. They are defined as the influence of combined factors on the test index. In fact, the "interaction effects" are reflections of mutual promotion or inhibition, and these effects are more or less existed in all physical phenomenon. In the statistical analysis of the results obtained from factorial experiments, the sparsity-of-effects principle states that a system is usually dominated by main effects (single factor) and low-order interactions. Therefore, it is most likely that main effects and two-factor interactions are the most significant responses in an experiment [45].

A majority of studies have shown that the dynamic responses of vehicle-bridge system are influenced by so many factors, including vehicle characteristics, pavement roughness, and bridge characteristics [46]. In this study, to efficiently reduce the experimental runs, the conventional
TABLE 2: Parameters of the bridge.

\begin{tabular}{lccccc}
\hline$L(\mathrm{~m})$ & $W(\mathrm{~m})$ & $I\left(\mathrm{~m}^{4}\right)$ & $A\left(\mathrm{~m}^{2}\right)$ & $E(\mathrm{MPa})$ & $\rho\left(\mathrm{kg} / \mathrm{m}^{3}\right)$ \\
\hline 30 & 12 & 1.98 & 6.23 & 34500 & 2600 \\
\hline
\end{tabular}

$L$ : length, $W$ : width, $I$ : moment of inertia, $E$ : modules of elasticity, and $\rho$ : density.

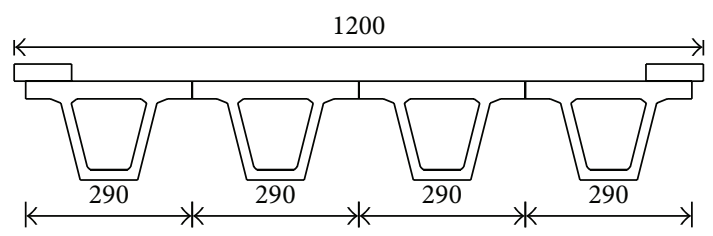

FIGURE 8: The cross-section of the bridge $(\mathrm{cm})$.

orthogonal design is divided into two phases. In the first phase, main effects (single factor) are analyzed without any interaction effects. Based on the results from the first phase, the interaction effects of some of the most important factors are discussed in the second phase.

4.2. Samples Selection. As we know, there are many types of highway bridges, including the girder bridge, the arch bridge, the cable-stayed bridge, and the suspension bridge. Of course, the simply supported girder bridge is the most common type. Based on the standard drawings issued by the Ministry of Transport of the People's Republic of China in 2008, a $30 \mathrm{~m}$-span bridge with small-box section has been selected as the fundamental sample of bridges. The damping ratio is assumed as 0.05 . The cross-section is in Figure 8 and its other parameters are listed in Table 2.

In highway bridges, the types of moving vehicles are various, which is significantly different from the type of vehicles in railway bridges. And it makes the problem of the vehicle-bridge coupled system become much more complex. Usually, there are three types of vehicles, including the small car, the bus or coach, and the loading truck. Apparently, due to their light weight, the first two types of vehicles may not be the main contributions on the dynamic responses. So the 3-axle loading truck has to be selected in this study. Its weight is 30 tons. It is seen in Figure 9 and Table 3.

Pavement roughness is the excitation source of the vehicle-bridge coupled vibration. For new bridges, the condition of the pavement is very good or good. So the maximum amplitude of the pavement roughness is assumed as $1 \mathrm{~cm}(\alpha=$ 0.2345 ) in this study.

Based on so many existing research results $[2,4,5,7-$ 9], twelve factors are considered and discussed, including the pavement roughness, the span length, width, mass, stiffness, and damping of the bridge, the mass, upper stiffness (suspension system), upper damping, lower stiffness, lower damping, and speed of the vehicle. And they are successively denoted by capital letters from A to L. All of these factors are listed in Table 4.

Considering computational efficiency, three levels are given for every factor. The value of parameters in fundamental models described above is thought as the second level. 
TABLE 3: Parameters of the three-axle loading truck.

\begin{tabular}{lccc}
\hline Parameters & Value & Parameters & Value \\
\hline Mass of truck body & $31800 \mathrm{~kg}$ & Upper stiffness (front axle) & $1200 \mathrm{kN} \cdot \mathrm{m}^{-1}$ \\
Mass of front wheel & $400 \mathrm{~kg}$ & Upper stiffness (middle/rear axle) & $2400 \mathrm{kN} \cdot \mathrm{m}^{-1}$ \\
Mass of middle/rear wheel & $600 \mathrm{~kg}$ & Upper damping (front axle) & $5 \mathrm{kN} \cdot \mathrm{s} \cdot \mathrm{m}^{-1}$ \\
Pitching moment of inertia & $40000 \mathrm{~kg} \cdot \mathrm{m}^{2}$ & Upper damping (middle $/$ rear axle) & $10 \mathrm{kN} \cdot \mathrm{s} \cdot \mathrm{m}^{-1}$ \\
Rolling moment of inertia & $10000 \mathrm{~kg} \cdot \mathrm{m}^{2}$ & Lower stiffness (front axle) & $2400 \mathrm{kN} \cdot \mathrm{m}^{-1}$ \\
Distance (front axle to center) & $4.60 \mathrm{~m}$ & Lower stiffness (middle $/$ rear axle) & $4800 \mathrm{kN} \cdot \mathrm{m}^{-1}$ \\
Distance (middle axle to center) & $0.36 \mathrm{~m}$ & Lower damping (front axle) & $6 \mathrm{kN} \cdot \mathrm{s} \cdot \mathrm{m}^{-1}$ \\
Distance (middle to rear axle) & $1.40 \mathrm{~m}$ & Lower damping (middle $/$ rear axle) & $12 \mathrm{kN} \cdot \mathrm{s} \cdot \mathrm{m}^{-1}$ \\
Wheel base & $1.80 \mathrm{~m}$ & & \\
\hline
\end{tabular}

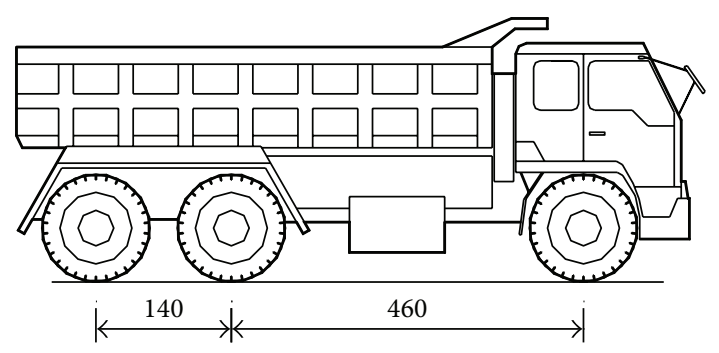

FIgURE 9: Three-axle loading truck $(\mathrm{cm})$.

TABLE 4: Factors description.

\begin{tabular}{ll}
\hline Factor & Description \\
\hline$A$ & Pavement roughness \\
$B$ & Span length of the bridge \\
$C$ & Width of the bridge \\
$D$ & Mass of the bridge \\
$E$ & Stiffness of the bridge \\
$F$ & Damping of the bridge \\
$G$ & Mass of the vehicle \\
$H$ & Upper stiffness of the vehicle \\
$I$ & Upper damping of the vehicle \\
$J$ & Lower stiffness of the vehicle \\
$K$ & Lower damping of the vehicle \\
$L$ & Speed of the vehicle \\
\hline
\end{tabular}

Then the first level and the third level are taken by $20 \%$ lower and $20 \%$ higher, respectively. For instance, three levels of the span length are $24 \mathrm{~m}\left(A_{1}, 30 \mathrm{~m} \times 0.8\right), 30 \mathrm{~m}\left(A_{2}\right)$, and $36 \mathrm{~m}$ $\left(A_{3}, 30 \mathrm{~m} \times 1.2\right)$. Of all these factors, the factors of width and speed have to be emphasized as follows. The simply supported girder bridge is assembled by many prefabricated small-box section girders. Three levels of the width are $9 \mathrm{~m}$ ( 3 girders), $12 \mathrm{~m}$ (4 girders), and $15 \mathrm{~m}$ (5 girders). And the speeds of the moving vehicle are assumed as $20 \mathrm{~m} / \mathrm{s}, 25 \mathrm{~m} / \mathrm{s}$, and $30 \mathrm{~m} / \mathrm{s}$, which are common in actual operation.

4.3. Numerical Simulations without Interaction. Firstly, the interaction has been ignored in this section. As for twelve factors and three levels for every factors, the orthogonal array $L_{27}\left(3^{13}\right)$ has been adopted. If only main effects (single

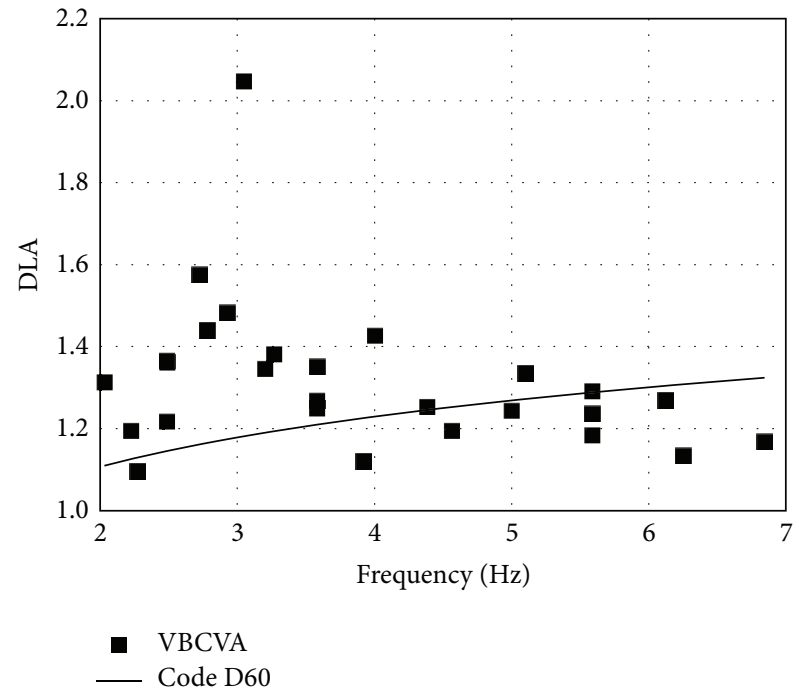

FIGURE 10: Relation between the DLA and the fundamental frequency.

factor) are considered, there is no mixture involved in the arrangement of factors. So they can be arranged successively. It is seen in Table 5.

All of these runs are analyzed by our own program VBCVA. The fundamental frequency $\left(f_{1}\right)$ of the bridge is the most important index of dynamics. The dynamic load allowance (DLA) is the common index to take account of the dynamic performance of the bridge traversed by moving vehicles in design and evaluation. For simplification, the comfort of pedestrians on the bridge and passengers in the vehicle is evaluated by the vibration accelerations of the bridge $\left(a_{b}\right)$ and the vehicle $\left(a_{v}\right)$ in general. Therefore, these four indices are obtained from a large number of results, and they are listed in Table 6.

In most of design codes of highway bridges, the dynamic load allowance (DLA) is defined as the function of the fundamental frequency of the bridge. Taking the current code (JTG D60-2004) [47] in China as an example, the values of DLA defined in the code are compared with that calculated by VBCVA (Figure 10).

Figure 10 shows that the differences between them are much more significant, especially for the frequency ranging 
TABLE 5: Orthogonal array $L_{27}\left(3^{13}\right)$ and the arrangement of factors.

\begin{tabular}{|c|c|c|c|c|c|c|c|c|c|c|c|c|c|}
\hline \multirow{2}{*}{ Run } & 1 & 2 & 3 & 4 & 5 & 6 & 7 & 8 & 9 & 10 & 11 & 12 & 13 \\
\hline & $A$ & $B$ & $C$ & $D$ & $E$ & $F$ & $G$ & $H$ & $I$ & $J$ & $K$ & $L$ & Non \\
\hline 1 & 1 & 1 & 1 & 1 & 1 & 1 & 1 & 1 & 1 & 1 & 1 & 1 & 1 \\
\hline 2 & 1 & 1 & 1 & 1 & 2 & 2 & 2 & 2 & 2 & 2 & 2 & 2 & 2 \\
\hline 3 & 1 & 1 & 1 & 1 & 3 & 3 & 3 & 3 & 3 & 3 & 3 & 3 & 3 \\
\hline 4 & 1 & 2 & 2 & 2 & 1 & 1 & 1 & 2 & 2 & 2 & 3 & 3 & 3 \\
\hline 5 & 1 & 2 & 2 & 2 & 2 & 2 & 2 & 3 & 3 & 3 & 1 & 1 & 1 \\
\hline 6 & 1 & 2 & 2 & 2 & 3 & 3 & 3 & 1 & 1 & 1 & 2 & 2 & 2 \\
\hline 7 & 1 & 3 & 3 & 3 & 1 & 1 & 1 & 3 & 3 & 3 & 2 & 2 & 2 \\
\hline 8 & 1 & 3 & 3 & 3 & 2 & 2 & 2 & 1 & 1 & 1 & 3 & 3 & 3 \\
\hline 9 & 1 & 3 & 3 & 3 & 3 & 3 & 3 & 2 & 2 & 2 & 1 & 1 & 1 \\
\hline 10 & 2 & 1 & 2 & 3 & 1 & 2 & 3 & 1 & 2 & 3 & 1 & 2 & 3 \\
\hline 11 & 2 & 1 & 2 & 3 & 2 & 3 & 1 & 2 & 3 & 1 & 2 & 3 & 1 \\
\hline 12 & 2 & 1 & 2 & 3 & 3 & 1 & 2 & 3 & 1 & 2 & 3 & 1 & 2 \\
\hline 13 & 2 & 2 & 3 & 1 & 1 & 2 & 3 & 2 & 3 & 1 & 3 & 1 & 2 \\
\hline 14 & 2 & 2 & 3 & 1 & 2 & 3 & 1 & 3 & 1 & 2 & 1 & 2 & 3 \\
\hline 15 & 2 & 2 & 3 & 1 & 3 & 1 & 2 & 1 & 2 & 3 & 2 & 3 & 1 \\
\hline 16 & 2 & 3 & 1 & 2 & 1 & 2 & 3 & 3 & 1 & 2 & 2 & 3 & 1 \\
\hline 17 & 2 & 3 & 1 & 2 & 2 & 3 & 1 & 1 & 2 & 3 & 3 & 1 & 2 \\
\hline 18 & 2 & 3 & 1 & 2 & 3 & 1 & 2 & 2 & 3 & 1 & 1 & 2 & 3 \\
\hline 19 & 3 & 1 & 3 & 2 & 1 & 3 & 2 & 1 & 3 & 2 & 1 & 3 & 2 \\
\hline 20 & 3 & 1 & 3 & 2 & 2 & 1 & 3 & 2 & 1 & 3 & 2 & 1 & 3 \\
\hline 21 & 3 & 1 & 3 & 2 & 3 & 2 & 1 & 3 & 2 & 1 & 3 & 2 & 1 \\
\hline 22 & 3 & 2 & 1 & 3 & 1 & 3 & 2 & 2 & 1 & 3 & 3 & 2 & 1 \\
\hline 23 & 3 & 2 & 1 & 3 & 2 & 1 & 3 & 3 & 2 & 1 & 1 & 3 & 2 \\
\hline 24 & 3 & 2 & 1 & 3 & 3 & 2 & 1 & 1 & 3 & 2 & 2 & 1 & 3 \\
\hline 25 & 3 & 3 & 2 & 1 & 1 & 3 & 2 & 3 & 2 & 1 & 2 & 1 & 3 \\
\hline 26 & 3 & 3 & 2 & 1 & 2 & 1 & 3 & 1 & 3 & 2 & 3 & 2 & 1 \\
\hline 27 & 3 & 3 & 2 & 1 & 3 & 2 & 1 & 2 & 1 & 3 & 1 & 3 & 2 \\
\hline
\end{tabular}

1: 1st level, 2: 2nd level, 3: 3rd level, and Non: no factor in this column.

from $2 \mathrm{~Hz}$ to $4 \mathrm{~Hz}$. Also, the DLAs obtained in different runs are not the same, even if the frequencies are almost the same. So the DLA is dependent on a lot of factors, other than just the fundamental frequency. At another point of view, it has been proved again that dynamic responses of the vehicle-bridge system should be thought as the multifactor problem.

In statistics, two methods are always used for data processing, range analysis and variance analysis. The first method has advantage of low cost, simple thought, and convenience to be popularized and applied. But, compared with variance analysis, the range analysis has two defects. Firstly, the error is hardly estimated. Secondly, the reliability cannot be determined. And it also cannot be used for regression analysis and design. Of course, the method of various analyses can avoid both defects. Then these two methods are described as follows, respectively.
The range of analysis is completed by two steps. At first, the ranges of every factor are calculated by [48]

$$
R_{j}=\max \left(k_{j 1}, k_{j 2}, \ldots, k_{j m}\right)-\min \left(k_{j 1}, k_{j 2}, \ldots, k_{j m}\right),
$$

where $k_{j m}$ is the mean value of the $j$ th factor with the $m$ th level, and $R_{j}$ is the range of the $j$ th factor. Then the trend between factors and the test index is plotted. The results can be seen in Table 7 and Figure 11.

Variance analysis is more rigorous. There are four steps to realize the variance analysis $[48,49]$.

(i) Step 1: as for every factors, calculate the sum of square of deviations $\left(S_{j}\right)$, the degree of freedom (dof, $f_{j}$ ), and the variance estimation $\left(\sigma_{j}\right)$.

(ii) Step 2: estimate the variance of the error $\left(\sigma_{e}\right)$. 
TABLE 6: Results of numerical simulations without interaction.

\begin{tabular}{|c|c|c|c|c|}
\hline Run & $f_{1}(\mathrm{~Hz})$ & DLA & $a_{b}\left(\mathrm{~m} / \mathrm{s}^{2}\right)$ & $a_{v}\left(\mathrm{~m} / \mathrm{s}^{2}\right)$ \\
\hline 1 & 5.59 & 1.183 & 0.3867 & 2.3001 \\
\hline 2 & 6.25 & 1.133 & 0.7283 & 3.2982 \\
\hline 3 & 6.84 & 1.168 & 0.7333 & 2.4512 \\
\hline 4 & 3.20 & 1.345 & 1.4651 & 3.1712 \\
\hline 5 & 3.58 & 1.268 & 0.7086 & 2.5815 \\
\hline 6 & 3.92 & 1.120 & 0.4376 & 1.6981 \\
\hline 7 & 2.03 & 1.312 & 0.8765 & 3.8239 \\
\hline 8 & 2.27 & 1.095 & 0.6762 & 1.5517 \\
\hline 9 & 2.49 & 1.365 & 0.5886 & 1.9558 \\
\hline 10 & 4.56 & 1.194 & 0.6982 & 2.5255 \\
\hline 11 & 5.10 & 1.335 & 0.5796 & 3.9891 \\
\hline 12 & 5.59 & 1.290 & 0.3568 & 2.5697 \\
\hline 13 & 3.58 & 1.249 & 0.6848 & 2.8135 \\
\hline 14 & 4.00 & 1.426 & 1.0353 & 4.9386 \\
\hline 15 & 4.38 & 1.252 & 1.0250 & 2.6898 \\
\hline 16 & 2.22 & 1.194 & 1.5957 & 2.9421 \\
\hline 17 & 2.49 & 1.217 & 1.0797 & 2.7304 \\
\hline 18 & 2.72 & 1.575 & 1.3255 & 2.7280 \\
\hline 19 & 5.00 & 1.244 & 0.8916 & 2.7037 \\
\hline 20 & 5.59 & 1.236 & 0.9152 & 4.0151 \\
\hline 21 & 6.12 & 1.269 & 0.7024 & 5.5762 \\
\hline 22 & 2.92 & 1.482 & 1.6800 & 3.9525 \\
\hline 23 & 3.27 & 1.381 & 1.2634 & 2.6892 \\
\hline 24 & 3.58 & 1.351 & 0.8484 & 3.6659 \\
\hline 25 & 2.49 & 1.361 & 1.0922 & 2.9921 \\
\hline 26 & 2.78 & 1.439 & 1.3170 & 2.4652 \\
\hline 27 & 3.05 & 2.047 & 2.2685 & 5.3437 \\
\hline
\end{tabular}

TABLE 7: Range analysis of numerical simulations without interaction.

\begin{tabular}{lcccccccccccc}
\hline Index & $A$ & $B$ & $C$ & $D$ & $E$ & $F$ & $G$ & $H$ & $I$ & $J$ & $K$ \\
\hline DLA & 0.202 & 0.173 & 0.106 & 0.088 & 0.101 & 0.033 & 0.127 & 0.186 & 0.062 & 0.068 & 0.154 & 0.060 \\
$a_{b}\left(\mathrm{~m} / \mathrm{s}^{2}\right)$ & 0.486 & 0.536 & 0.249 & 0.189 & 0.121 & 0.090 & 0.112 & 0.319 & 0.154 & 0.315 & 0.119 & 0.426 \\
$a_{v}\left(\mathrm{~m} / \mathrm{s}^{2}\right)$ & 1.175 & 0.322 & 0.368 & 0.285 & 0.162 & 0.427 & 1.331 & 0.993 & 0.232 & 0.420 & 0.204 & 0.598 \\
\hline
\end{tabular}

(iii) Step 3: obtain the test static $F$ and compare the $F$ with its critical value $F_{\alpha}$ for given significance level $\alpha$.

(iv) Step 4: for simplicity, the variance analysis table is listed, including the process and the results.

All of them are calculated as follows:

$$
\begin{gathered}
S=\sum_{i=1}^{a}\left(y_{i}-\bar{y}\right)^{2}=\sum_{i=1}^{a} y_{i}^{2}-\frac{1}{a}\left(\sum_{i=1}^{a} y_{i}\right)^{2}, \\
S_{j}=\frac{a}{b} \sum_{k=1}^{b}\left(\bar{y}_{j k}-\bar{y}\right)^{2}=\frac{a}{b} \sum_{k=1}^{b} y_{j k}^{2}-\frac{1}{a}\left(\sum_{i=1}^{a} y_{i}\right)^{2}, \\
F_{j}=\frac{\sigma_{j}}{\sigma_{e}}=\frac{S_{j} / f_{j}}{S_{e} / f_{e}}
\end{gathered}
$$

in which $y_{i}$ is the index result of the $i$ th run and $y_{j k}$ is the index result of the $j$ th factor with the $k$ th level. Also, $S_{e}$ and $f_{e}$ denote, respectively, the sum of square of deviations and the degree of freedom of the error.

It has to be noted that the error is resulted from all of the vacant columns in the orthogonal array. Also, the accuracy increases with the increasing dof of the error. Therefore, if the significance level of one factor is larger than 0.25 , it can be included as the error. Of course, that may not be the same in different situations. All of the results are listed in Table 8.

It can be concluded that the influence of factors on different indices are listed as follows.

(i) For DLA of the bridge,

$$
A>H>B>K>G>C>E>D>J>I>L>F \text {. }
$$

(ii) For vibration acceleration of the bridge,

$$
B>A>L>H>J>C>I>D>E>K>G>F \text {. }
$$




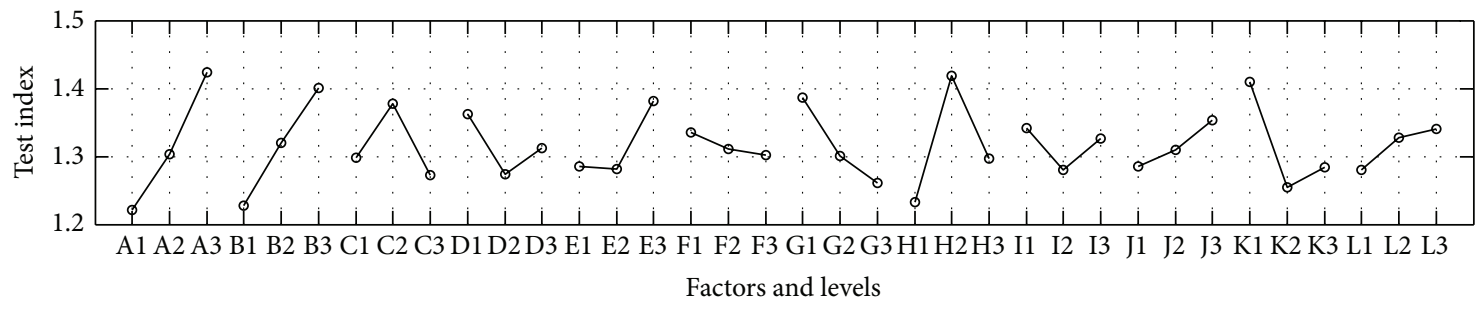

(a) Trend plot between factors and the DLA of the bridge.

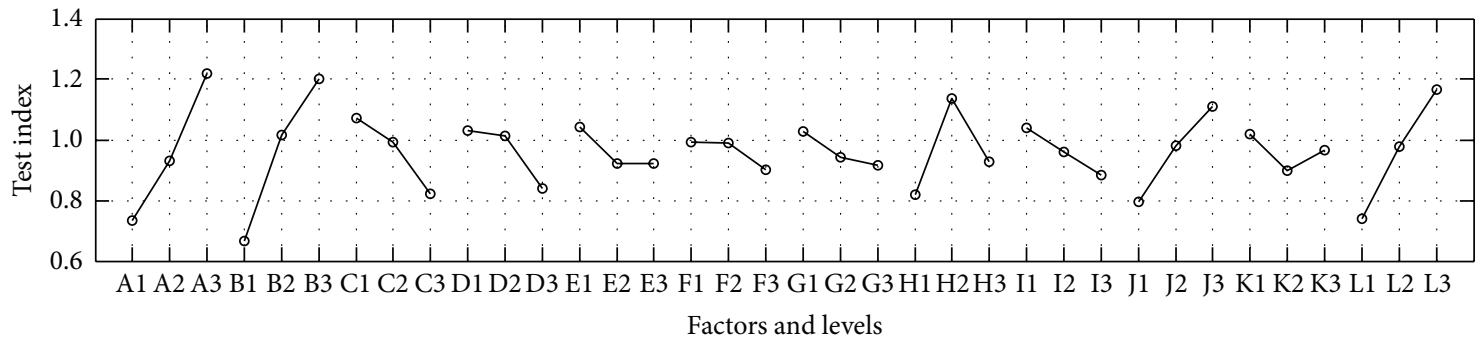

(b) Trend plot between factors and the acceleration of the bridge.

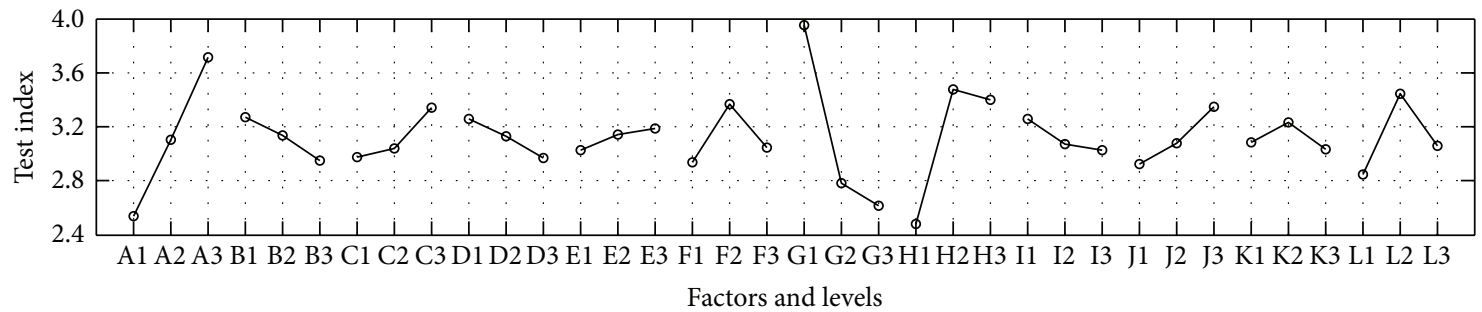

(c) Trend plot between factors and the acceleration of the vehicle body.

FIGURE 11: Trend plot between factors and the test index.

(iii) For vibration acceleration of the vehicle,

$G>A>H>L>F>J>C>B>D>I>K>E$.

Obviously, for different indices, the most important influence factors are different. The sensitive factors are the pavement roughness, the span length, and the mass of the vehicle for the indices of the DLA, the vibration accelerations of the bridge and vehicle, respectively. It has to be noted that the DLA is the relative value of the dynamic response and the static response, while the vibration acceleration is the absolute value. It is the result of influence differences between the DLA and the vibration acceleration of the bridge, even though they are correlated in some extent.

4.4. Numerical Simulations considering Interaction. As mentioned earlier, the interaction almost exists in all of physical phenomena. When the interaction is so small, it can be ignored in application. However, as for research, we do not know whether the interaction can be ignored or not at first. As a result, the orthogonal design is introduced to solve this problem.

Based on the results from the above section, the first five most important factors influencing the DLA are selected. They are the pavement roughness $(A)$, the upper stiffness of the vehicle $(H)$, the span length of the bridge $(B)$, the lower damping of the vehicle $(K)$, and the mass of the vehicle $(G)$. Meanwhile, due to the calculation cost and the existing orthogonal array, the number of levels is determined as two for each factor. The second level in the above section is taken as the first level in this section, which is based on the fundamental models. And the second level is defined as $20 \%$ higher than the first level. According to the sparsity-of-effects principle, only the lower order interaction (two factors) is considered.

To avoid the mixture, the most important factor has to be arranged at first. It can be seen in Table 9.

The methods are the same as that in the above section. The results of range analysis and variance analysis are listed in Tables 10 and 11, respectively.

It can be concluded that the influence of factors on different indices are listed as follows.

(i) For DLA of the bridge,

$$
\begin{aligned}
& G>A>B>H>A \times B>A \times K>A \times G \\
& >H \times B>A \times H>K>H \times K>H \times G>B \times K .
\end{aligned}
$$

(ii) For vibration acceleration of the bridge,

$$
\begin{gathered}
B>A>H>G>A \times B>H \times G>K>A \times G \\
>A \times K>A \times H>H \times B>H \times K>B \times K .
\end{gathered}
$$


TABLE 8: Various analyses of numerical simulations without interaction.

(a) Dynamic load allowance (DLA) of the bridge

\begin{tabular}{|c|c|c|c|c|c|c|c|c|}
\hline \multirow{2}{*}{ Factor } & \multirow{2}{*}{$S_{j}$} & \multirow{2}{*}{ dof } & \multicolumn{3}{|c|}{ Initial } & \multicolumn{3}{|c|}{ Modification } \\
\hline & & & $\sigma_{j}$ & $F$ & $\alpha$ & $\sigma_{j}$ & $F$ & $\alpha$ \\
\hline$A$ & 0.1861 & 2 & 0.0931 & 49.35 & 0.05 & 0.0931 & 41.55 & 0.01 \\
\hline$B$ & 0.1344 & 2 & 0.0672 & 35.64 & 0.05 & 0.0672 & 30.00 & 0.01 \\
\hline C & 0.0545 & 2 & 0.0273 & 14.45 & 0.10 & 0.0273 & 12.17 & 0.05 \\
\hline$D$ & 0.0351 & 2 & 0.0175 & 9.30 & 0.10 & 0.0175 & 7.83 & 0.05 \\
\hline E & 0.0586 & 2 & 0.0293 & 15.54 & 0.10 & 0.0293 & 13.09 & 0.05 \\
\hline$F$ & 0.0052 & 2 & 0.0026 & 1.38 & $>0.25$ & - & - & - \\
\hline G & 0.0754 & 2 & 0.0377 & 20.00 & 0.05 & 0.0377 & 16.84 & 0.05 \\
\hline$H$ & 0.1605 & 2 & 0.0802 & 42.55 & 0.05 & 0.0802 & 35.82 & 0.01 \\
\hline$I$ & 0.0188 & 2 & 0.0094 & 5.00 & 0.25 & 0.0094 & 4.21 & 0.25 \\
\hline$J$ & 0.0211 & 2 & 0.0106 & 5.60 & 0.25 & 0.0106 & 4.72 & 0.10 \\
\hline K & 0.1214 & 2 & 0.0607 & 32.18 & 0.05 & 0.0607 & 27.10 & 0.01 \\
\hline$L$ & 0.0182 & 2 & 0.0091 & 4.84 & 0.25 & 0.0091 & 4.07 & 0.25 \\
\hline Error & 0.0038 & 2 & 0.0019 & & & 0.0022 & & \\
\hline Sum & 0.8932 & 26 & & & & & & \\
\hline
\end{tabular}

(b) Vibration accelerations of the bridge $\left(a_{b}\right)$ and the vehicle $\left(a_{v}\right)$

\begin{tabular}{|c|c|c|c|c|c|c|c|c|c|}
\hline \multirow{2}{*}{ Factor } & \multicolumn{2}{|c|}{$S_{j}$} & \multirow{2}{*}{ dof } & \multicolumn{3}{|c|}{ Bridge $a_{b}$} & \multicolumn{3}{|c|}{ Vehicle $a_{v}$} \\
\hline & $a_{b}$ & $a_{v}$ & & $\sigma_{j}$ & F & $\alpha$ & $\sigma_{j}$ & F & $\alpha$ \\
\hline$A$ & 1.0772 & 6.2119 & 2 & 0.5386 & 349.08 & 0.01 & 3.1060 & 182.75 & 0.01 \\
\hline$B$ & 1.3357 & 0.4694 & 2 & 0.6678 & 432.86 & 0.01 & 0.2347 & 13.81 & 0.10 \\
\hline C & 0.2923 & 0.6948 & 2 & 0.1461 & 94.71 & 0.05 & 0.3474 & 20.44 & 0.05 \\
\hline$D$ & 0.1977 & 0.3681 & 2 & 0.0989 & 64.07 & 0.05 & 0.1841 & 10.83 & 0.10 \\
\hline$E$ & 0.0858 & 0.1244 & 2 & 0.0429 & 27.80 & 0.05 & 0.0622 & 3.66 & 0.25 \\
\hline$F$ & 0.0478 & 0.8906 & 2 & 0.0239 & 15.49 & 0.10 & 0.4453 & 26.20 & 0.05 \\
\hline G & 0.0613 & 9.4647 & 2 & 0.0306 & 19.86 & 0.05 & 4.7323 & 278.44 & 0.01 \\
\hline$H$ & 0.4733 & 5.4874 & 2 & 0.2366 & 153.37 & 0.01 & 2.7437 & 161.43 & 0.01 \\
\hline$I$ & 0.1068 & 0.2728 & 2 & 0.0534 & 34.62 & 0.05 & 0.1364 & 8.03 & 0.25 \\
\hline$J$ & 0.4521 & 0.8116 & 2 & 0.2260 & 146.50 & 0.01 & 0.4058 & 23.88 & 0.05 \\
\hline K & 0.0637 & 0.2004 & 2 & 0.0318 & 20.63 & 0.05 & 0.1002 & 5.90 & 0.25 \\
\hline$L$ & 0.8217 & 1.6547 & 2 & 0.4108 & 266.29 & 0.01 & 0.8273 & 48.68 & 0.05 \\
\hline Error & 0.0031 & 0.0340 & 2 & 0.0015 & & & 0.0170 & & \\
\hline Sum & 5.0183 & 26.6849 & 26 & & & & & & \\
\hline
\end{tabular}

(iii) For vibration acceleration of the vehicle,

$$
\begin{aligned}
& A>G>B>H>H \times B>H \times G>A \times G \\
& >A \times B>A \times K>K>A \times H>H \times K>B \times K .
\end{aligned}
$$

Obviously, apart from the lower damping of the vehicle $(K)$, other four main factors are still the most important influences on the test indices, including the DLA of the bridge, the vibration accelerations of the bridge and the vehicle. And the interaction effects are less. Maybe they can be neglected in engineering application. In addition, there are some differences for the importance order of factors between the results from this section and the above section. However, general trend has been little changed. Of course, the later one is more accurate and reliable, due to considering the interaction other than just main effects.
Similarly, for different testing indices, the influence of each factor is not the same.

4.5. Results and Discussions. According to numerical simulations, the sensitivity of each factor for different indices is not the same. Therefore, we should pay more attention to various factors for different purpose in the design of bridges and vehicles. For example, if the bridge is mainly for pedestrians, the acceleration of the bridge is related with their comfort. Then the span length and the pavement roughness should be noted. If the riding comfort is the primary consideration, maybe we should focus on the pavement roughness and the mass of the moving vehicle. However, as for safety of the bridge, the important factors include the pavement roughness, span length of the bridge, mass, and upper stiffness of the vehicle. 
TABLE 9: Orthogonal array $L_{16}\left(2^{15}\right)$ and the arrangement of factors.

\begin{tabular}{|c|c|c|c|c|c|c|c|c|c|c|c|c|c|c|c|}
\hline \multirow{2}{*}{ Run } & 1 & 2 & 3 & 4 & 5 & 6 & 7 & 8 & 9 & 10 & 11 & 12 & 13 & 14 & 15 \\
\hline & $A$ & $H$ & $A \times H$ & $B$ & $A \times B$ & $H \times B$ & Non & $K$ & $A \times K$ & $H \times K$ & Non & $B \times K$ & $H \times G$ & $A \times G$ & $G$ \\
\hline 1 & 1 & 1 & 1 & 1 & 1 & 1 & 1 & 1 & 1 & 1 & 1 & 1 & 1 & 1 & 1 \\
\hline 2 & 1 & 1 & 1 & 1 & 1 & 1 & 1 & 2 & 2 & 2 & 2 & 2 & 2 & 2 & 2 \\
\hline 3 & 1 & 1 & 1 & 2 & 2 & 2 & 2 & 1 & 1 & 1 & 1 & 2 & 2 & 2 & 2 \\
\hline 4 & 1 & 1 & 1 & 2 & 2 & 2 & 2 & 2 & 2 & 2 & 2 & 1 & 1 & 1 & 1 \\
\hline 5 & 1 & 2 & 2 & 1 & 1 & 2 & 2 & 1 & 1 & 2 & 2 & 1 & 1 & 2 & 2 \\
\hline 6 & 1 & 2 & 2 & 1 & 1 & 2 & 2 & 2 & 2 & 1 & 1 & 2 & 2 & 1 & 1 \\
\hline 7 & 1 & 2 & 2 & 2 & 2 & 1 & 1 & 1 & 1 & 2 & 2 & 2 & 2 & 1 & 1 \\
\hline 8 & 1 & 2 & 2 & 2 & 2 & 1 & 1 & 2 & 2 & 1 & 1 & 1 & 1 & 2 & 2 \\
\hline 9 & 2 & 1 & 2 & 1 & 2 & 1 & 2 & 1 & 2 & 1 & 2 & 1 & 2 & 1 & 2 \\
\hline 10 & 2 & 1 & 2 & 1 & 2 & 1 & 2 & 2 & 1 & 2 & 1 & 2 & 1 & 2 & 1 \\
\hline 11 & 2 & 1 & 2 & 2 & 1 & 2 & 1 & 1 & 2 & 1 & 2 & 2 & 1 & 2 & 1 \\
\hline 12 & 2 & 1 & 2 & 2 & 1 & 2 & 1 & 2 & 1 & 2 & 1 & 1 & 2 & 1 & 2 \\
\hline 13 & 2 & 2 & 1 & 1 & 2 & 2 & 1 & 1 & 2 & 2 & 1 & 1 & 2 & 2 & 1 \\
\hline 14 & 2 & 2 & 1 & 1 & 2 & 2 & 1 & 2 & 1 & 1 & 2 & 2 & 1 & 1 & 2 \\
\hline 15 & 2 & 2 & 1 & 2 & 1 & 1 & 2 & 1 & 2 & 2 & 1 & 2 & 1 & 1 & 2 \\
\hline 16 & 2 & 2 & 1 & 2 & 1 & 1 & 2 & 2 & 1 & 1 & 2 & 1 & 2 & 2 & 1 \\
\hline
\end{tabular}

1: 1st level, 2: 2nd level (be equal to the 2nd and the 3rd level in above section, resp.), and Non: no factor in this column.

TABLE 10: Range analysis of numerical simulations considering interaction.

\begin{tabular}{lccccccccccccc}
\hline Index & $A$ & $H$ & $A \times H$ & $B$ & $A \times B$ & $H \times B$ & $K$ & $A \times K$ & $H \times K$ & $B \times K$ & $H \times G$ & $A \times G$ & $G$ \\
\hline DLA & 0.101 & 0.063 & 0.009 & 0.285 & 0.027 & 0.012 & 0.009 & 0.021 & 0.008 & 0.002 & 0.006 & 0.019 & 0.111 \\
$a_{b}\left(\mathrm{~m} / \mathrm{s}^{2}\right)$ & 0.222 & 0.117 & 0.013 & 0.607 & 0.053 & 0.010 & 0.018 & 0.013 & 0.001 & 0.001 & 0.036 & 0.014 & 0.099 \\
$a_{v}\left(\mathrm{~m} / \mathrm{s}^{2}\right)$ & 0.640 & 0.350 & 0.039 & 0.545 & 0.063 & 0.171 & 0.048 & 0.050 & 0.029 & 0.009 & 0.112 & 0.068 & 0.636 \\
\hline
\end{tabular}

In short, it has to be noted that the pavement roughness is the essential factor.

Comparing the acceleration of the bridge with that of the vehicle, the former one is more related with the span length, while the latter one is more related with the mass of the vehicle. Actually, the span length of the bridge is significantly related with its fundamental frequency. And the mass of the vehicle will influence natural frequencies of the vehicle. Therefore, in nature, the determined factors are natural frequencies of the bridge and moving vehicles. Also, it is consistent with the conclusion obtained from the simplified theoretical derivation in Section 2. Based on this consistency, the proposed method, orthogonal experimental design, has been verified. And the results are reliable.

For vehicle design, stiffness is more important than the damping of the suspension system, especially the upper stiffness. According to the structural dynamics, the damping of the vehicle has less influence on its natural frequencies than the stiffness. Meanwhile, it has been proved that the frequency is the main factor.

Using the method of orthogonal experimental design, the interaction effects are so small that they can be neglected in engineering application.

Furthermore, the plot of relation between DLA and the fundamental frequency shows that the DLA is dependent on many factors, and more synthetical and accurate formulas should be proposed in the code. In addition, for comfort of pedestrians and passengers, the empirical formulas of accelerations of the bridge and the vehicle could be added based on the proposed method in this study.

\section{Conclusions}

To get a good understanding of the dynamic responses of the simply supported girder bridge to moving vehicular loads or vehicles, theoretical derivations are presented based on simplified models of the vehicle-bridge coupled vibration system; then some numerical simulations based on the proposed method of the orthogonal experimental design in batches have been done by our own program VBCVA.

Firstly, according to simplified theoretical derivations, three factors are proved as the most important factors to determine dynamic responses. They are the mass ratio of the vehicle and the bridge $(\kappa)$, the frequency ratio of the vehicle and the bridge $(\gamma)$, and the ratio of disturbance frequency related with the speed and the frequency of the bridge $(\alpha)$. It has to be noted that the roughness has not been considered in simplified models.

Secondly, based on the modal synthesis method, the thought of our own program VBCVA has been given in detail. Combining both advantages of the commercial software ANSYS and MATLAB, the bridge model is found by ANSYS, while the vehicle model and the roughness model are established by MATLAB. It can be used for calculating the 
TABLE 11: Various analyses of numerical simulations considering interaction.

(a) Dynamic load allowance (DLA) of the bridge

\begin{tabular}{|c|c|c|c|c|c|c|c|c|}
\hline \multirow{2}{*}{ Factor } & \multirow{2}{*}{$S_{j}$} & \multirow{2}{*}{ dof } & \multicolumn{3}{|c|}{ Initial } & \multicolumn{3}{|c|}{ Modification } \\
\hline & & & $\sigma_{j}$ & $F$ & $\alpha$ & $\sigma_{j}$ & $F$ & $\alpha$ \\
\hline$A$ & 0.0411 & 1 & 0.0411 & 26.04 & 0.05 & 0.0411 & 68.61 & 0.01 \\
\hline$H$ & 0.0160 & 1 & 0.0160 & 10.12 & 0.10 & 0.0160 & 26.66 & 0.01 \\
\hline$A \times H$ & 0.0003 & 1 & 0.0003 & 0.21 & $>0.25$ & - & - & - \\
\hline$B$ & 0.3257 & 1 & 0.3257 & 206.42 & 0.01 & 0.3257 & 543.94 & 0.01 \\
\hline$A \times B$ & 0.0030 & 1 & 0.0030 & 1.90 & $>0.25$ & 0.0030 & 5.00 & 0.10 \\
\hline$H \times B$ & 0.0006 & 1 & 0.0006 & 0.36 & $>0.25$ & - & - & - \\
\hline K & 0.0003 & 1 & 0.0003 & 0.21 & $>0.25$ & - & - & - \\
\hline$A \times K$ & 0.0018 & 1 & 0.0018 & 1.11 & $>0.25$ & 0.0018 & 2.92 & 0.25 \\
\hline$H \times K$ & 0.0003 & 1 & 0.0003 & 0.17 & $>0.25$ & - & - & - \\
\hline$B \times K$ & 0.0000 & 1 & 0.0000 & 0.01 & $>0.25$ & - & - & - \\
\hline$H \times G$ & 0.0001 & 1 & 0.0001 & 0.08 & $>0.25$ & - & - & - \\
\hline$A \times G$ & 0.0014 & 1 & 0.0014 & 0.90 & $>0.25$ & 0.0014 & 2.38 & 0.25 \\
\hline G & 0.0493 & 1 & 0.0493 & 31.26 & 0.05 & 0.0493 & 82.37 & 0.01 \\
\hline Error & 0.0032 & 2 & 0.0016 & & & 0.0006 & & \\
\hline Sum & 0.4431 & 15 & & & & & & \\
\hline
\end{tabular}

(b) Vibration acceleration of the bridge $\left(a_{b}\right)$

\begin{tabular}{|c|c|c|c|c|c|c|c|c|}
\hline \multirow{2}{*}{ Factor } & \multirow{2}{*}{$S_{j}$} & \multirow{2}{*}{ dof } & \multicolumn{3}{|c|}{ Initial } & \multicolumn{3}{|c|}{ Modification } \\
\hline & & & $\sigma_{j}$ & F & $\alpha$ & $\sigma_{j}$ & F & $\alpha$ \\
\hline$A$ & 0.1977 & 1 & 0.1977 & 32528.26 & 0.01 & 0.1977 & 36136.85 & 0.01 \\
\hline$H$ & 0.0545 & 1 & 0.0545 & 8967.12 & 0.01 & 0.0545 & 9961.91 & 0.01 \\
\hline$A \times H$ & 0.0007 & 1 & 0.0007 & 107.79 & 0.01 & 0.0007 & 119.75 & 0.01 \\
\hline$B$ & 1.4716 & 1 & 1.4716 & 242142.36 & 0.01 & 1.4716 & 269004.93 & 0.01 \\
\hline$A \times B$ & 0.0111 & 1 & 0.0111 & 1828.29 & 0.01 & 0.0111 & 2031.12 & 0.01 \\
\hline$H \times B$ & 0.0004 & 1 & 0.0004 & 65.65 & 0.01 & 0.0004 & 72.93 & 0.01 \\
\hline K & 0.0013 & 1 & 0.0013 & 207.47 & 0.01 & 0.0013 & 230.48 & 0.01 \\
\hline$A \times K$ & 0.0007 & 1 & 0.0007 & 119.36 & 0.01 & 0.0007 & 132.61 & 0.01 \\
\hline$H \times K$ & 0.0000 & 1 & 0.0000 & 1.10 & $>0.25$ & - & - & - \\
\hline$B \times K$ & 0.0000 & 1 & 0.0000 & 0.50 & $>0.25$ & - & - & - \\
\hline$H \times G$ & 0.0052 & 1 & 0.0052 & 848.12 & 0.01 & 0.0052 & 942.20 & 0.01 \\
\hline$A \times G$ & 0.0008 & 1 & 0.0008 & 129.02 & 0.01 & 0.0008 & 143.34 & 0.01 \\
\hline G & 0.0389 & 1 & 0.0389 & 6404.66 & 0.01 & 0.0389 & 7115.17 & 0.01 \\
\hline Error & 0.0000 & 2 & 0.0000 & & & 0.0000 & & \\
\hline Sum & 1.7828 & 15 & & & & & & \\
\hline
\end{tabular}

(c) Vibration acceleration of the vehicle $\left(a_{v}\right)$

\begin{tabular}{|c|c|c|c|c|c|c|c|c|}
\hline \multirow{2}{*}{ Factor } & \multirow{2}{*}{$S_{j}$} & \multirow{2}{*}{ dof } & \multicolumn{3}{|c|}{ Initial } & \multicolumn{3}{|c|}{ Modification } \\
\hline & & & $\sigma_{j}$ & F & $\alpha$ & $\sigma_{j}$ & $F$ & $\alpha$ \\
\hline$A$ & 1.6400 & 1 & 1.6400 & 14.80 & 0.10 & 1.6400 & 51.80 & 0.01 \\
\hline$H$ & 0.4914 & 1 & 0.4914 & 4.44 & 0.25 & 0.4914 & 15.52 & 0.01 \\
\hline$A \times H$ & 0.0062 & 1 & 0.0062 & 0.06 & $>0.25$ & - & - & - \\
\hline$B$ & 1.1866 & 1 & 1.1866 & 10.71 & 0.10 & 1.1866 & 37.48 & 0.01 \\
\hline$A \times B$ & 0.0159 & 1 & 0.0159 & 0.14 & $>0.25$ & - & - & - \\
\hline$H \times B$ & 0.1175 & 1 & 0.1175 & 1.06 & $>0.25$ & 0.1175 & 3.71 & 0.10 \\
\hline K & 0.0094 & 1 & 0.0094 & 0.08 & $>0.25$ & - & - & - \\
\hline$A \times K$ & 0.0099 & 1 & 0.0099 & 0.09 & $>0.25$ & - & - & - \\
\hline$H \times K$ & 0.0034 & 1 & 0.0034 & 0.03 & $>0.25$ & - & - & - \\
\hline$B \times K$ & 0.0003 & 1 & 0.0003 & 0.00 & $>0.25$ & - & - & - \\
\hline$H \times G$ & 0.0498 & 1 & 0.0498 & 0.45 & $>0.25$ & 0.0498 & 1.57 & 0.25 \\
\hline
\end{tabular}


(c) Continued.

\begin{tabular}{lccccccc}
\hline \multirow{2}{*}{ Factor } & \multirow{2}{*}{$S_{j}$} & dof & \multicolumn{3}{c}{ Initial } & \multicolumn{2}{c}{ Modification } \\
& & & $\sigma_{j}$ & $F$ & $\sigma_{j}$ & - \\
\hline$A \times G$ & 0.0182 & 1 & 0.0182 & 0.16 & $>0.25$ & - & 1.6199 \\
$G$ & 1.6199 & 1 & 1.6199 & 14.62 & 0.10 & 0.0317 & 51.17 \\
Error & 0.2216 & 2 & 0.1108 & & & & \\
\hline Sum & 5.3900 & 15 & & & & \\
\hline
\end{tabular}

cases of multilanes and multivehicles (both in longitudinal direction and transverse direction). Also, the number of axles or vehicles is not limited. Therefore, this program has to be thought of as convenient and powerful enough for the analysis of vehicle-bridge coupled vibration problems.

Thirdly, on the basis of the orthogonal experimental design, both the main effects and the interaction effects can be studied. For different indices of dynamic responses, the influences of each factor are not the same. However, the pavement roughness is assumed as the most important factor. In addition, dynamic responses of the bridge and the vehicle are much more dependent on their own fundamental frequency, respectively. Furthermore, the interaction effects have proved to be so small that they can be neglected in engineering application.

In the end, it has to be emphasized that the proposed method of the orthogonal experimental design in batches greatly reduces calculation cost. And it is efficient and rational enough to study multifactor problems.

The proposed method is used for not only the analysis of influence factors, but also the analysis of regression. And it can be applied in all types of bridges, other than just the simply supported bridge. Furthermore, it provides a good way to obtain more rational empirical formulas of the DLA and other dynamic responses, which may be adopted in the codes of design and evaluation.

\section{Conflict of Interests}

The authors declare that there is no conflict of interests regarding the publication of this paper.

\section{Acknowledgments}

The research reported herein was sponsored by the China Scholarship Council (the 2013 China State-Sponsored Postgraduate Study Abroad Program) and the National Natural Science Foundation of China (no. 50678051, no. 51108132). The authors would like to express their deep gratitude to all the sponsors for the financial aid.

\section{References}

[1] S. G. M. Neves, A. F. M. Azevedo, and R. Calçada, "A direct method for analyzing the vertical vehicle-structure interaction," Engineering Structures, vol. 34, pp. 414-420, 2012.
[2] L. Frýba, Vibration of Solids and Structures under Moving Loads, Thomas Telford, Prague, Czech Republic, 1972.

[3] J. E. Akin and M. Mofid, "Numerical solution for response of beams with moving mass," Journal of Structural Engineering, vol. 115, no. 1, pp. 120-131, 1989.

[4] A. H. Fuller, "Impact in highway bridges," Transactions of ASCE, vol. 95, pp. 56-62, 1929.

[5] R. Cantieni, Dynamic Load Tests on Highway Bridges in Switzerland-60 Years Experience of EMPA, EMPA, Dübendorf, Switzerland, 1983.

[6] J. R. Billing and R. Green, "Design provisions for dynamic loading of highway bridges," Transportation Research Record, vol. 950, pp. 94-103, 1984.

[7] C. H. Wang, Study on the impact force acted on highway bridges by moving vehicle loads [PhD thesis], Harbin Institute of Technology, Harbin, China, 2007.

[8] H. Jung, G. Kim, and C. Park, "Impact factors of bridges based on natural frequency for various superstructure types," KSCE Journal of Civil Engineering, vol. 17, no. 2, pp. 458-464, 2013.

[9] W. H. Walker and A. S. Veletsos, Response of Simple-Span Highway Bridges to Moving Vehicles, University of Illinois Engineering Experiment Station, University of Illinois at UrbanaChampaign, Champaign, Ill, USA, 1963.

[10] J. A. Nieto-Ramírez and A. S. Veletsos, Response of Three-Span Continuous Highway Bridges to Moving Vehicles, University of Illinois Engineering Experiment Station, University of Illinois at Urbana-Champaign, Urbana, Ill, USA, 1966.

[11] T.-L. Wang, D. Huang, and M. Shahawy, "Dynamic response of multigirder bridges," Journal of Structural Engineering, vol. 118, no. 8, pp. 2222-2238, 1992.

[12] K. Henchi, M. Fafard, M. Talbot, and G. Dhatt, "An efficient algorithm for dynamic analysis of bridges under moving vehicles using a coupled modal and physical components approach," Journal of Sound and Vibration, vol. 212, no. 4, pp. 663-683, 1998.

[13] W. H. Guo and Y. L. Xu, "Fully computerized approach to study cable-stayed bridge-vehicle interaction," Journal of Sound and Vibration, vol. 248, no. 4, pp. 745-761, 2001.

[14] L. Kwasniewski, H. Li, J. Wekezer, and J. Malachowski, "Finite element analysis of vehicle-bridge interaction," Finite Elements in Analysis and Design, vol. 42, no. 11, pp. 950-959, 2006.

[15] L. Deng and C. S. Cai, "Development of dynamic impact factor for performance evaluation of existing multi-girder concrete bridges," Engineering Structures, vol. 32, no. 1, pp. 21-31, 2010.

[16] N. Zhang and H. Xia, "Dynamic analysis of coupled vehiclebridge system based on inter-system iteration method," Computers and Structures, vol. 114-115, pp. 26-34, 2013.

[17] D. B. Ashebo, Evaluation of dynamic loads for highway bridges [Ph.D. thesis], The Hong Kong Polytechnic University, Hong Kong, 2006. 
[18] J. T. Gaunt and C. D. Sutton, Highway Bridge Vibration Studies, Purdue University, West Lafayette, Ind, USA, 1981.

[19] W.-S. Yoo, C.-H. Lee, W.-B. Jeong, and S.-H. Kim, "Development and application of new evaluation system for ride comfort and vibration on railway vehicles," Journal of Mechanical Science and Technology, vol. 19, no. 7, pp. 1469-1477, 2005.

[20] S. Živanović, A. Pavic, and P. Reynolds, "Vibration serviceability of footbridges under human-induced excitation: a literature review," Journal of Sound and Vibration, vol. 279, no. 1-2, pp. 174, 2005.

[21] C. W. Roeder, K. Barth, and A. Bergman, Improved Live Load Deflection Criteria for Steel Bridges, Transportation Research Board, Washington, DC, USA, 2002.

[22] K. Youcef, T. Sabiha, D. El Mostafa, D. Ali, and M. Bachir, "Dynamic analysis of train-bridge system and riding comfort of trains with rail irregularities," Journal of Mechanical Science and Technology, vol. 27, no. 4, pp. 951-962, 2013.

[23] L. Frýba, Vibration of Solids and Structures under Moving Loads, Thomas Telford, Prague, Czech Republic, 3rd edition, 1999.

[24] A. N. Krylov, Mathematical Collection of Papers of the Academy of Sciences, vol. 61, Matematischeskii Sbornik Akademii Nauk, 1905.

[25] S. P. Timoshenko, "Forced vibration of prismatic bars," Izvestiya Kievskogo Politekhnicheskogo Instituta, no. 59, pp. 163-203, 1908 (Russian).

[26] S. C. E. Inglis, A Mathematical Treatise on Vibrations in Railway Bridges, The University Press, Cambridge, Mass, USA, 1934.

[27] V. Koloušek and R. F. McLean, Dynamics in Engineering Structures, Butterworths, 1973.

[28] X. D. Shao, X. Y. Cheng, and L. F. Li, Bridge Design \& Computation, China Communication Press, Beijing, China, 2007.

[29] K. A. Deng, Dynamic response of certain types of highway bridges to moving vehicles [Ph.D. thesis], University of Ottawa, Ottawa, Canada, 1998.

[30] A. K. Chopra, Dynamics of Structures, Prentice Hall, Bakersfield, Calif, USA, 4th edition, 2011.

[31] T. D. Gillespie, "Fundamentals of Vehicle Dynamics," SAE Technical Paper, Washington, DC, USA, 1992.

[32] Y. F. Song, Dynamics of Highway Bridges, China Communication Press, Beijing, China, 2000, (Chinese).

[33] G. Strang and K. Aarikka, Introduction to Applied Mathematics, Wellesley-Cambridge, Wellesley, Mass, USA, 1986.

[34] J. Cheng, H. Zhu, S. Zhong, Y. Zeng, and X. Dong, "Finite-time $H_{\infty}$ control for a class of Markovian jump systems with modedependent time-varying delays via new Lyapunov functionals," ISA Transactions, vol. 52, no. 6, pp. 768-774, 2013.

[35] J. W. Cao, "Improved delay-dependent stability conditions for mimo networked control systems with nonlinear perturbations," The Scientific World Journal, vol. 2014, Article ID 196927, 4 pages, 2014.

[36] D. Huang, "Vehicle-induced vibration of steel deck arch bridges and analytical methodology," Journal of Bridge Engineering, vol. 17, no. 2, pp. 241-248, 2012.

[37] J. Cheng, H. Zhu, Y. Ding, S. Zhong, and Q. Zhong, "Stochastic finite-time boundedness for Markovian jumping neural networks with time-varying delays," Applied Mathematics and Computation, vol. 242, pp. 281-295, 2014.

[38] S. Jerath and S. Gurav, "Road surface roughness generation by power spectral density in bridge design," in Proceedings of the Structures Congress, pp. 1-7, 2008.
[39] H. Honda, Y. Kajikawa, and T. Kobori, "Spectra of road surface roughness on bridges," Journal of the Structural Division, vol. 108, no. 9, pp. 1956-1966, 1982.

[40] E. S. Hwang and A. S. Nowak, "Simulation of dynamic load for bridges," Journal of Structural Engineering, vol. 117, no. 5, pp. 1413-1434, 1991.

[41] Q. F. Gao, Z. L. Wang, B. Q. Guo, H. R. Bu, and W. Xiong, "Design on dynamic performance of highway bridges to moving vehicular loads," Key Engineering Materials, vol. 574, pp. 43-51, 2014.

[42] B. Q. Guo, Study on driving comfort of cable-stayed bridges with moving vehicles [Master, thesis], Harbin Institute of Technology, Harbin, China, 2013.

[43] R. Mee, A Comprehensive Guide to Factorial Two-Level Experimentation, Springer, Berlin, Germany, 2009.

[44] L. Q. Ren, Optimum Design and Analysis of Experiments, Higher Education Press, Beijing, China, 2nd edition, 2003, (Chinese).

[45] C. F. J. Wu and M. S. Hamada, Experiments: Planning, Analysis, and Optimization, Wiley Series in Probability and Statistics, John Wiley \& Sons, Hoboken, NJ, USA, 2nd edition, 2011.

[46] D. I. McLean and M. L. Marsh, Dynamic Impact Factors for Bridges, Transportation Research Board, Washington, DC, USA, 1998.

[47] China PR Ministry of Communications, JTG D60-2004 General Code for Design of Highway Bridges and Culverts, China Communication Press, Beijing, China, 2004.

[48] T. P. Ryan, Modern Engineering Statistics: Solutions Manual to Accompany, John Wiley \& Sons, Hoboken, NJ, USA, 2000.

[49] D. C. Montgomery, Design and Analysis of Experiments, John Wiley \& Sons, Hoboken, NJ, USA, 2008. 


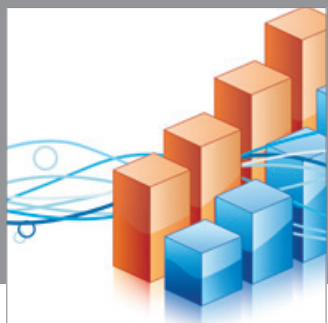

Advances in

Operations Research

mansans

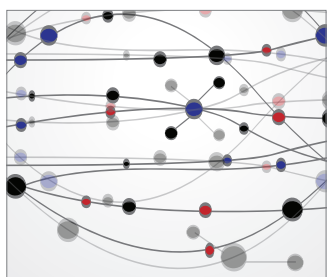

The Scientific World Journal
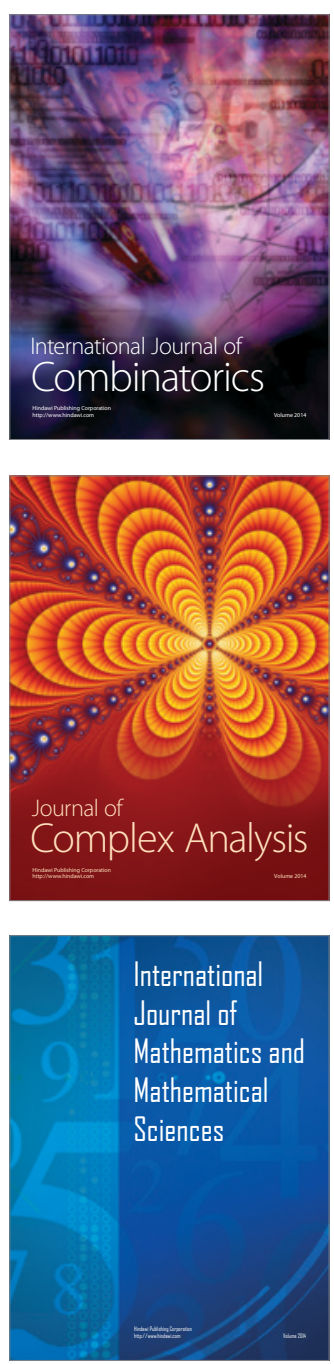
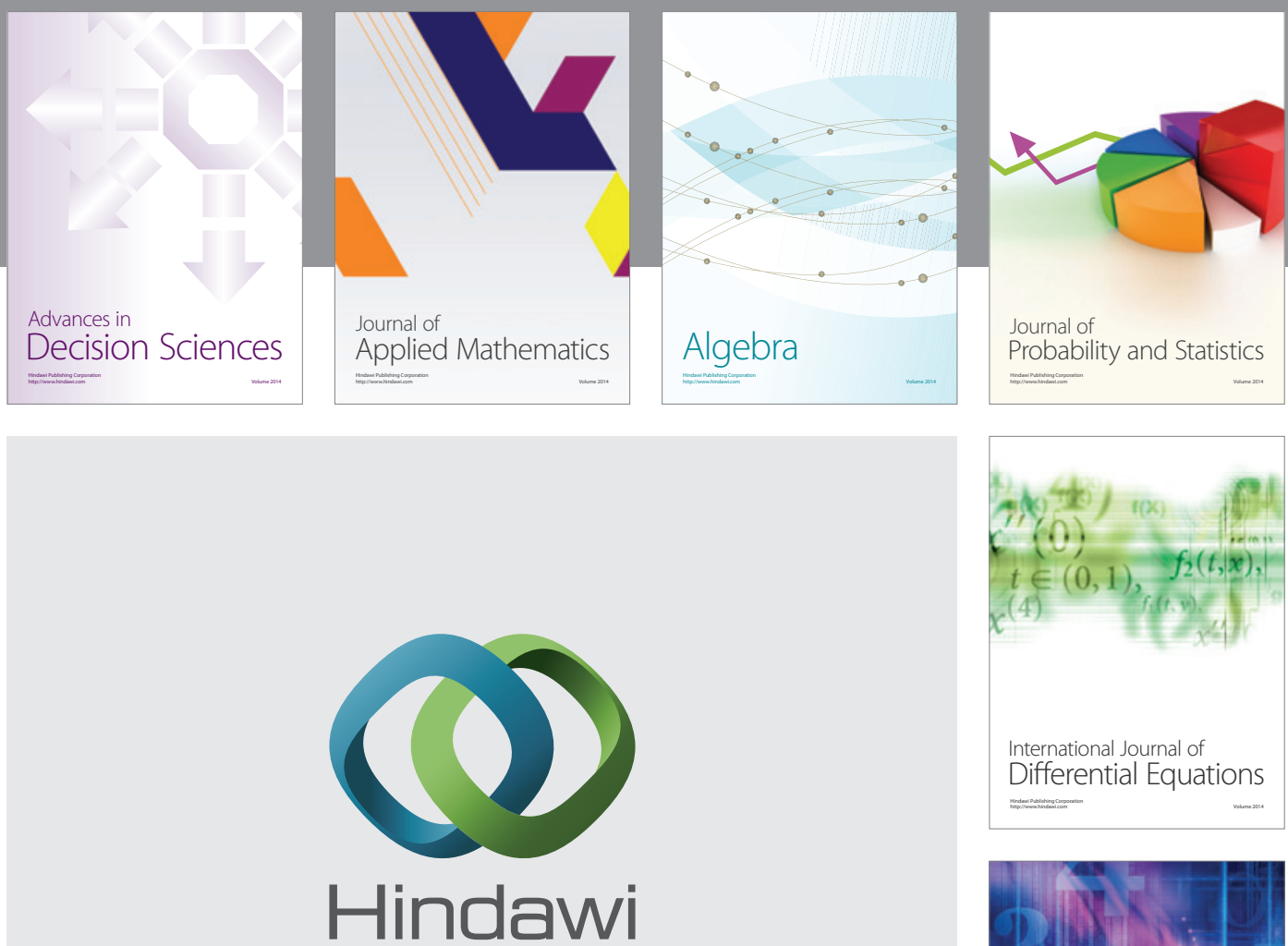

Submit your manuscripts at http://www.hindawi.com
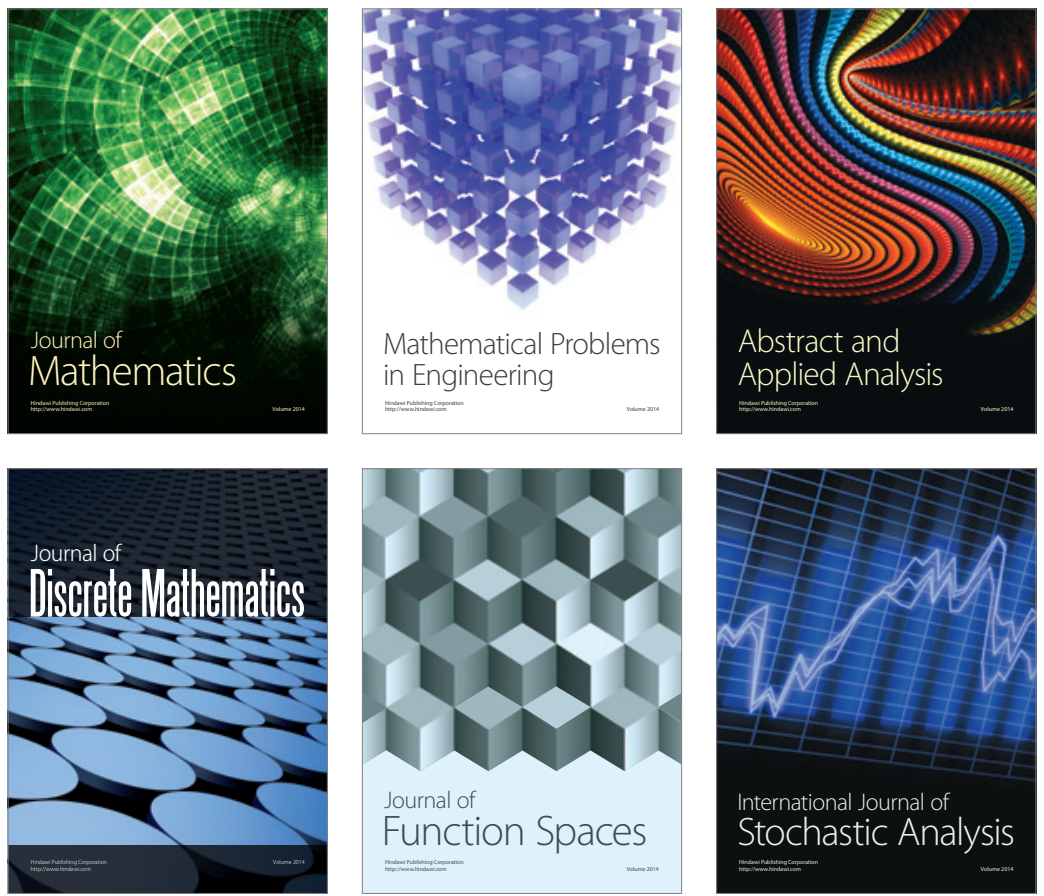

Journal of

Function Spaces

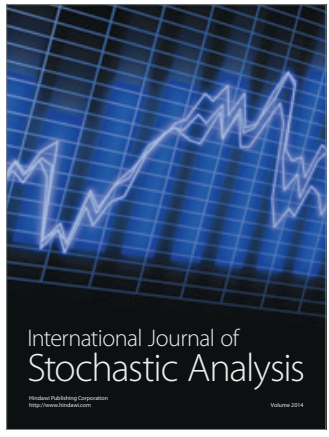

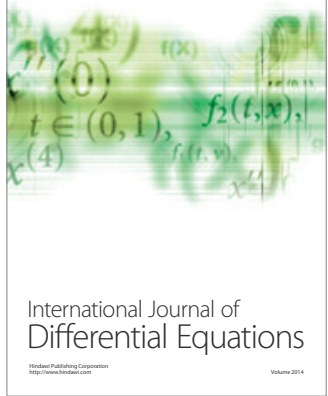
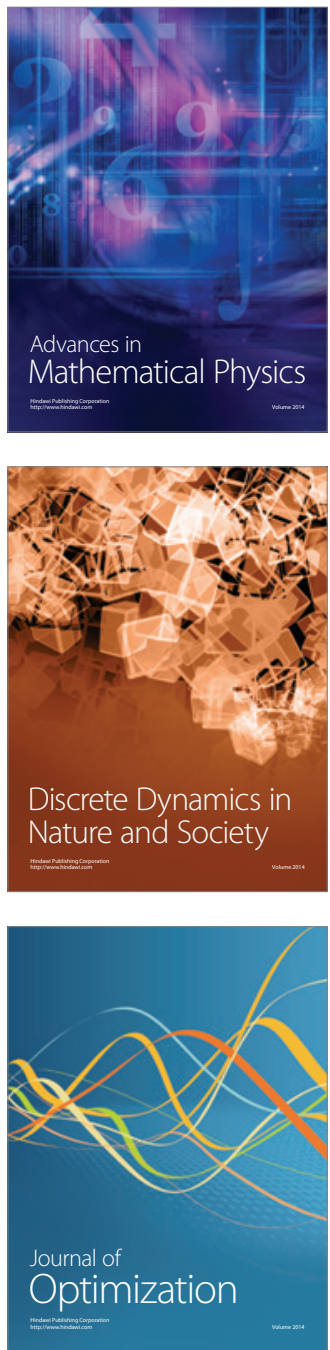